\title{
Application hybrid GSAPSO Technique for AGC in Inter Connected Power System with Generation Rate Constant
}

\author{
PABITRA MOHAN DASH ${ }^{1}$, ASINI BALIARSINGH ${ }^{2},{ }^{*}$ SANGRAM KESHORI MOHAPTRA ${ }^{3}$ \\ ${ }^{1}$ Department of Electrical Engineering, BEC, Bhubaneswar, Odisha, INDIA \\ ${ }^{2}$ Department of Electrical Engineering, GCE, Kalahandi, Odisha, INDIA \\ ${ }^{3}$ Department of Electrical Engineering, GCE, Keonjhar, Odisha, INDIA
}

\begin{abstract}
An attempt has been taken in this work to effectively implement the combination of GSA and PSO (hGSA-PSO) technique towards AGC in two-area inter-connected power systems with generation rate constraint (GRC) is considered. For the design and analysis, a initial attempt has been taken to optimize parameters of proportional-integral-derivative (PID) controller in two area non-reheat thermal power system employing GSA and hGSA-PSO algorithm with ITAE objective function. A sensitivity studies carried out for the robustness of the system by changing the operating condition and variation of the parameter and generation rate constant $(\mathrm{GRC}= \pm 0.05$ and \pm 0.025$)$ is considered. The performances of the proposed controller has been evaluated with those of some previously published optimization techniques such as GA and BOFA based optimized controller parameters for the same power system. This study of the present work is extended to two area multi sources power system to test the robustness analysis of the system by comparing the hGSA-PSO optimized to PI controller with same structure of system by selecting with and without GRC for showing the dynamic performance analysis of the system in term of settling time and overshoot.
\end{abstract}

Keywords: Multi-area power system, hGSA-PSO, Automatic Generation Control (AGC), Generation Rate Constraint (GRC).

Received: March 15, 2021. Revised: November 18, 2021. Accepted: December 20, 2021. Published: December 31, 2021.

\section{Introduction}

In the recent advances of technology, the modern electric power system containing several utilities and multiple power generating areas are interconnected. In order to achieve a better electrical power quality, power exchange among various utilities is done through tie lines. For successful operation of any power system, generation must be balanced with the demand subjected to the system losses will be minimum. Simultaneously the system frequency, power exchange and the operating point must be maintained at the scheduled value. In this situation AGC which can control the continuous records of the system frequency and tie-line power-flow to maintain them in an approaching point of the nominal value [1]. It calculates the net change in power generation and deviation in frequency whose linear combination is called as Area Control Error (ACE) that is taken as the controlled output of AGC. Thus, the generator adjusts its position such that frequency of the system and power flow in the tie line during disturbances is nearest to the scheduled value [2]. In the present trend, most of the Engineer's prefer classical PID controller due to its robust adaptive performance load variation against change of parameters, cost effectiveness, reliability and simplicity with less user skill requirements. Most of researchers are suggested in the literature AI based techniques for optimization of controller parameters. The performances of AGC has been compared and shown in literature using various conventional controllers such as P, PI, PID [3-5]. It is also attempted many researcher AGC system of the inter connected power system by using the modern control theory, neural network, fuzzy system theory and ANFIS approach etc.[3-6]. Bacterial Forging Optimization Algorithm (BOFA) based controllers found to give a better response in comparison to GA based controller in non-reheat multi area thermal power systems [7]. Imperialist Competitive Algorithm (ICA) based PID controller parameters has been optimized for the inter connected multi area power system [8]. For optimization of PI controller parameters with Differential Evolution by (DE), the ITAE objective functions are modified with damping ratio and settling time [9]. Its performances are compared with those of BOFA and GA based PI controllers to report its supremacy [10]. Firefly Algorithm (FA) is a populationbased search algorithm newly developed in 
which is inspired by flashing behaviour of fireflies [11]. GSA one of the heuristic methods and it is efficient can solve non-linear and non-convex optimization problems successfully whose efficacy over other recent techniques are demonstrated in [12]. GSA has demonstrated itself as global optimization techniques by keeping balance between exploitation/exploration in search region to provide a nearly optimal solution. Optimization techniques like Gravitational search algorithm (GSA) are confined to exploitation of relative areas only [12-14]. Therefore, instead of considering them alone for global optimization they can be hybridized with other optimization techniques before implementing them in modern multi area interconnected power system analysis.

Keeping in view to the above facts, an effort has been taken in the current work to hybridize GSA and PSO techniques (hGSAPSO) towards automatic generation control of multi area inter connected power system. At the initial stage an attempt is taken to minimize ITAE criterion employing GSA with PID controller for each area. Then fine- tuning of controller's parameters found from GSA is done by employing PSO. Finally, both GSA and PSO are hybridized to obtain a faster result. The entire design is compared with published results of some techniques like Genetic Algorithm and BOFA [15]. Lastly the technique is implemented for three unequal models in presence of generation rate constraints (GRC).

\section{Modeling of the system}

The figure-1 show the two-area thermal power plant (each of $2000 \mathrm{MW}$ rating and 1000MW nominal loading) which is widely used in interconnected non-reheat thermal power system is taken in the model for the design and analysis proposes [15].

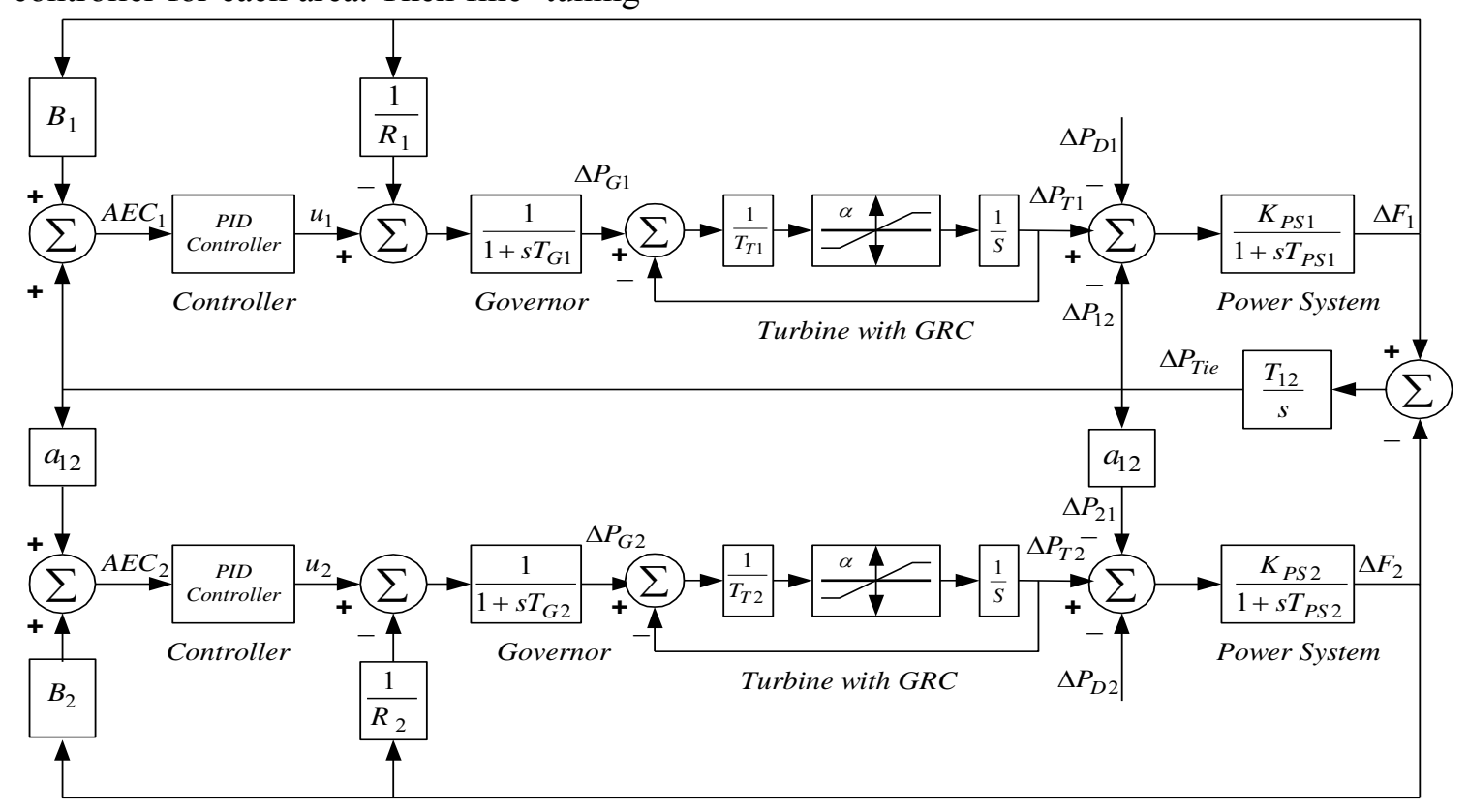

Figure-1 Two area thermal power plant

$\Delta \mathrm{F}_{1} \& \Delta \mathrm{F}_{2}=$ system frequency deviations

$\Delta \mathrm{G}_{1} \& \Delta \mathrm{G}_{2}=$ Governor out-puts (p.u)

$\mathrm{T}_{\mathrm{T} 1} \& \mathrm{~T}_{\mathrm{T} 2}=$ Turbine time constants $(\mathrm{sec})$

$\mathrm{T}_{\mathrm{G} 1} \& \mathrm{~T}_{\mathrm{G} 2}=$ Speed governor time constants $(\mathrm{sec})$

$\mathrm{T}_{12}=$ Synchronising co-efficient

$\mathrm{R}_{1} \& \mathrm{R}_{2}=$ Governor Speed regulation parameters (pu hz)

$\mathrm{u}_{1} \& \mathrm{u}_{2}=$ control outputs of controllers

$\mathrm{AEC}_{1} \& \mathrm{AEC}_{2}=$ Area control errors

$\mathrm{B}_{1} \& \mathrm{~B}_{2}=$ Frequency bias parameters
$\Delta \mathrm{T}_{1} \& \Delta \mathrm{T}_{2}=$ Changes in turbine out-puts

$\Delta D_{1} \& \Delta D_{2}=$ Changes in Load demands

$\Delta \mathrm{P}_{\mathrm{Tie}}=$ Increments in tie line power (p.u)

$\mathrm{K}_{\mathrm{PS} 1} \& \mathrm{~K}_{\mathrm{PS} 2}=$ gains of power system

$\mathrm{T}_{\mathrm{PS} 1} \& \mathrm{~T}_{\mathrm{PS} 2}=$ time constant of power system $(\mathrm{sec})$

$\Delta \mathrm{P}_{\mathrm{V} 1} \& \Delta \mathrm{P}_{\mathrm{V} 2}=$ p.u change in governor valve position

$\mathrm{D}=$ damping constant of hybrid power system 
Generation Rate Constraint (GRC) is the specific maximum rate (usually $2-5 \%$ per min for a thermal plant) at which power generation can change in thermal power plants. Various parameters are shown in Appendix-A. There are three inputs and two outputs in each area comprising generator, turbine and speed governing system. Controller inputs $\left(\mathrm{u}_{1} \& \mathrm{u}_{2}\right)$ are considered as input $\left(\Delta P_{\text {ref }}\right)$ where as generator frequency $\Delta \mathrm{F}$ and Area Control Error (ACE) given by equation (1) are the output of the system.

$$
A E C=B \Delta F+\Delta P_{T i e}
$$

Hear, $B$ represents the frequency bias parameter. For each component of an area, transfer functions are used in the model for simplicity in frequency-domain analyses, Turbine and Governor Transfer functions are represented by equation-2 and equation-3 as follows.

$$
\begin{gathered}
G_{T}(s)=\frac{\Delta P_{T}(s)}{\Delta P_{V}(s)}=\frac{1}{1+s T_{T}} \\
G_{G}(s)=\frac{\Delta P_{V}(s)}{\Delta P_{G}(s)}=\frac{1}{1+s T_{G}}
\end{gathered}
$$

There are two inputs $\Delta P_{\text {ref }} \& \Delta F$ and one output $\Delta P_{G}(s)$ of the speed governing system given by [2]

$$
\Delta P_{G}(s)=\Delta P_{r e f}(s)-\frac{1}{R} \Delta F(s)
$$

Transfer function representing generator and load [2]:

$$
G_{P}(s)=\frac{K_{P}}{1+s T_{P}}
$$

Where $K_{P}=1 / D$ and $T_{P}=2 H / f D$.

There are two inputs $\Delta P_{T}(s) \& \Delta P_{D}(s)$ with one out put $\Delta F(s)$ for the generator load system which is taken as per [2]:

$$
\Delta F(s)=G_{P}(s)\left[\Delta P_{T}(s)-\Delta P_{D}(s)\right]
$$

\section{Gravitational Search Algorithm (GSA)}

This Algorithm is heuristic approach which inspiration of Newton's laws of gravity and motion [12]. Here agents are taken as objects where as their executions are measured by their masses. The gravitational force gives rise to an attraction and hence causing a global movement among all agents approaching in the direction of the object of heavier mass representing an optimal solution in its domain. In the exploitation step of the algorithm the object having heavier mass, moves slower than that of lighter mass. In this algorithm there are four specifications (i.e. position of mass, inertial masses, active and passive gravitational mass) for each agent. The position of masses corresponding to the solution of the problem. However, fitness functions are employed to find out the gravitational and inertia masses. This shows that, navigation of the algorithm is properly adjusted by gravitational and inertia masses. Masses are follow the law of gravity as well as the law of motion [13-14] which are highlighted below.

\subsection{Law of Gravity}

Every particle attracts every other particle in the universe with a force varying directly as the product of the masses and inversely as the square of the distance between them R. As per the reference article [14] has been discussed about the that $\mathrm{R}$ gives the superior result as per the allexperiment cases as compared to $\mathrm{R}^{2}$ experiment performance.

\subsection{Law of Motion}

The velocity of any mass is equal to summation of the fraction of its preceding velocity and acceleration. The acceleration is the ratio of the force acted on the system to the mass of inertia.

In a system having ' $n$ ' agents, the $i^{\text {th }}$ position $(X)_{i}$ of an agent is given as

$$
X_{i}=\left(x_{i}^{1}, \ldots \ldots ., x_{i}^{d}, \ldots \ldots . x_{i}^{n}\right) \quad \text { For } i=1,2 \ldots \ldots n
$$

$x_{i}^{d}=$ position of $i^{\text {th }}$ agent along $d^{\text {th }}$ dimension.

When time $=\mathrm{t} \mathrm{sec}$, the force acting on mass ' $i$ ' from mass ' $j$ ' is given by

$$
F_{i j}^{d}(t)=G(t) \frac{M_{p i}(t)^{*} M_{a j}(t)}{R_{i j}(t)+\in}\left(x_{j}^{d}(t)-x_{i}^{d}(t)\right)
$$




$$
\begin{aligned}
& M_{a j}=\text { active gravitational mass w.r.t to } \mathrm{j}^{\text {th }} \\
& \text { agent } \\
& \qquad M_{p i}=\text { passive gravitational mass w.r.t to } \\
& \mathrm{i}^{\text {th }} \text { agent } \\
& \quad G(t)=\text { gravitational constant at time }=t \\
& \quad \in=\text { small constant } \\
& \quad R_{i j}(t)=\text { Euclidian distance between } \mathrm{i}^{\text {th }}
\end{aligned}
$$$$
\text { and } \mathrm{j}^{\text {th }} \text { agents given by- }
$$

$$
R_{i j}(t)=\left\|X_{i}(t), X_{j}(t)\right\|_{2}
$$

In GSA algorithm it is assumed that the net force acting on $i^{\text {th }}$ agent in $d^{\text {th }}$ dimension is the sum of random weights of $d^{\text {th }}$ components of forces exerted from other agents. Such stochastic characteristic is given by-

$$
F_{i}^{d}(t)=\sum_{j=1, j \neq i}^{n} \operatorname{rand}_{j} F_{i j}^{d}(t)
$$

Where, rand is the unspecified number which belongs to $[0,1]$. It is used for providing a randomized characteristic to the search process $a_{i}^{d}(t)$ is the acceleration of the $\mathrm{i}^{\text {th }}$ agent in $d^{\text {th }}$ direction at time $=\mathrm{t}$ and is given as

$$
a_{i}^{d}(t)=\frac{F_{i}^{d}(t)}{M_{i i}(t)}
$$

Here $M_{i i}(t)$ represents the inertia mass of $\mathrm{i}^{\text {th }}$ agent at time $=t$.

The velocity and position of an object are updated as

$$
\begin{aligned}
& v_{i}^{d}(t+1)=\operatorname{rand}_{i}{ }^{*} v_{i}^{d}(t)+a_{i}^{d}(t) \\
& x_{i}^{d}(t+1)=x_{i}^{d}(t)+v_{i}^{d}(t+1)
\end{aligned}
$$

Where, $r a n d_{i}$ is the uniform random variable such that $0<\operatorname{rand}_{\mathrm{i}}<1$

At the beginning stage, initialization of gravitational constant $G$ is done. It is reduced with respect to the time for controlling the search accuracy which is communicated in terms of $\mathrm{G}_{0}, \mathrm{t}$, $\mathrm{T}$ and $\alpha$ where, $\mathrm{G}_{0}=$ initial value, $\mathrm{t}=$ time to number of iterations, $\mathrm{T}=$ number of iterations, and constant $\alpha=$ constant' given by equation- 14 .

$$
G(t)=G_{0} e^{(-\alpha t / T)}
$$

The Fitness function has employed to evaluate Gravitational mass and Inertial masses where a heavier masse as calculated by employing the map of fitness indicates an efficient agent. It is updating as follows

$$
M_{a i}=M_{p i}=M_{i i}=M_{i} \text { Where } i=1,2, . . n \text {. }
$$

$$
m_{i}(t)=\frac{\operatorname{fit}_{i}(t)-\operatorname{worst}(t)}{\operatorname{best}(t)-\operatorname{worst}(t)}
$$

$$
M_{i}(t)=\frac{m_{i}(t)}{\sum_{j=1}^{N} m_{j}(t)}
$$

The best(t) of the minimization problem is represented in terms of $\mathrm{fit}_{i}(t)$ which is represented as fitness value of $i^{\text {th }}$ agent at time ' $t$ '

$$
\begin{gathered}
\operatorname{Best}(t)=\min _{j \in\{1 \ldots n\}} f i t_{j}(t) \\
\operatorname{Worst}(t)=\max _{j \in(1 \ldots n)} f i t_{j}(t)
\end{gathered}
$$

Here decreasing the no. of agents with respect to lapse of Eq. (10) and applying the forces of a group of agents with higher masses to other, a compromise between exploration and exploitation can be achieved and GSA performances can be improved. At the beginning, trapping in local optima can be avoided by using GSA where the K best agents attract the other. $\mathrm{K}$ best agents represent the set of first $K$ agents corresponding to the best fitness value and the biggest mass ' $k$ '. At the beginning the preliminary value $\mathrm{K}_{0}$ is taken in the time varying function and which will be decreases with time.The exploration is made to disappear gradually and exploitation is fade into by lapse of iterations. However, force is applied by every agent at beginning but $\mathrm{K}_{\text {best }}$ linearly decreases with respect to time. Finally, force is applied by only one agent to other agents and equation-10 is modified as

$$
F_{i}^{d}(t)=\sum_{j \in K b e s t, j \neq i} \operatorname{rand}_{j} F_{i j}^{d}(t)
$$

The different steps of the algorithm are highlighted as follows-

Step 1: Identification of search space with initialized the agent

Initilization of $i^{\mathrm{h}}$ agent and $\mathrm{d}^{\text {th }}$ dimenssion of $\mathrm{n}$ space can be represented as

$$
X_{i}=\left(x_{i}^{1}, \ldots \ldots . . x_{i}^{d}, \ldots \ldots x_{i}^{n}\right)
$$

Step 2: The best finess can be computed in each agent 
The best fitness and worst fitness value of fitness compuation are

$$
\operatorname{Best}(t)=\min _{j \in\{1 \ldots n\}} f i t_{j}(t) \quad \operatorname{Worst}(t)=\max _{j \in(1 . . n)} \operatorname{fit}_{j}(t)
$$

Step 3: The gravitational constant $G$ can be computed

The graviational constnt $\mathrm{G}$ with time ' $\mathrm{t}$ ' can be represented as

$\mathrm{G}(\mathrm{t})=\mathrm{G} 0$ e $(-\alpha \mathrm{t} / \mathrm{T})$

Step 4: Mass of agents is updated as

$$
\begin{aligned}
& M_{a i}=M_{p i}=M_{i i}=M_{i} \text { Where } i=1,2,3-------n \\
& m_{i}(t)=\frac{f i t_{i}(t)-\operatorname{worst}(t)}{\operatorname{best}(t)-\operatorname{worst}(t)}, M_{i}(t)=\frac{m_{i}(t)}{\sum_{j=1}^{N} m_{j}(t)}
\end{aligned}
$$

Step 5: Acceleration of agents is calculated as $a_{i}^{d}(t)=\frac{F_{i}^{d}(t)}{M_{i i}(t)}$ Where the total force of ith agent $F_{i}^{d}(t)=\sum_{j \in k \text { best }, j \neq i} \operatorname{rand}_{j} F_{i j}^{d}(t)$

Step 6: Velocities and positions of agents are updated as

$$
\begin{aligned}
& v_{i}^{d}(t+1)=\operatorname{rand}_{i}{ }^{*} v_{i}^{d}(t)+a_{i}^{d}(t), \\
& x_{i}^{d}(t+1)=x_{i}^{d}(t)+v_{i}^{d}(t+1)
\end{aligned}
$$

Step 7: The repeatation of step-1 to step-6 will be continue until iterations maximum limit reached

\section{Particle Swarm Optimization Algorithm (PSO)}

PSO is one of the population-based optimization techniques under a large category of swarm intelligence techniques which is used to obtain improved solutions within a less computational time in various optimization problems. It uses individuals called as particle which fly through the search space with a certain velocity adjusted according to its flying experiences in the light of that of the other particles. It makes great efforts to achieve by following traits from its successful peers. Every particle is capable enough to remember the best position in the search space visited by it through its memory. The best fitness Position is called $\mathrm{P}$ best and the overall best position of all the particles is called $\mathrm{g}$ best.

Summarization of the search method [16-17]

- $\quad \mathrm{P}_{\text {best }}$ and $\mathrm{g}$ best agents get closer to the global optima gradually by the use of different directions in spite of their different initial positions.
- In this method, the modified position of the agent being continuous which is used for this problem. For applying this method to discrete problems, $\mathrm{XY}$ position and velocity grids will be used.

- The searching procedures being consistent the method is easily applicable to mixed integer and nonlinear optimization problems containing state variables in continuous and discrete modes along with continuous axes, grids for XY positions and velocities.

calculation of velocity and position for each particle can done in a modified form by considering the current velocity along with the distance between Pbest ${ }_{j, g}$ to gbest ${ }_{g}$ as follows [16]

$v_{j, g}^{(t+1)}=w^{*} v_{j, g}^{(t)}+c_{1 * \eta}() *\left(\right.$ pbest $\left._{j, g}-x_{j, g}^{(t)}\right)+c_{2} * r_{2}() *\left(\right.$ gbest $\left._{g}-x_{j, g}^{(t)}\right)$

$$
x_{j, g}^{(t+1)}=x_{j, g}^{t}+v_{j, g}^{(t+1)}
$$

Where,

$n$ represent as no. of particles $\mathrm{j}(1,2,3 \ldots)$ for a particular swarm

$m$ represented as no. of components of velocity $g$ $(1,2,3 \ldots .$.$) in a particle$

$t$ represented as no. of iterations

$v_{j, g}^{(t)}=g^{\text {th }}$ component velocity of particle $j$ at iteration $t, V_{g}^{\min } \leq v_{j, g}^{(t)} \leq V_{g}^{\max }$

$w=$ inertial weight factor

$c_{1}, c_{2}=$ positive constants representing cognitive and social acceleration factors respectively and which can be find out the relative drag of pbest and gbest

$r_{1}, r_{2}=$ random numbers taken in the interval $(0$, 1) which can support the stochastically changing these pulls.

$x_{j, g}^{(t)}=g^{\text {th }}$ component of position of $\mathrm{j}^{\text {th }}$ particle at $\mathrm{i}^{\text {th }}$ iteration

pbest $_{j}=$ best fitness position of particle $j$

gbest $_{g}=$ best fitness position of the group

$d$-dimensional vector $x_{j}=\left(\begin{array}{lll}x_{j, 1}, & \left.x_{j, 2}, \ldots \ldots, \mathrm{x}_{\mathrm{j}, d}\right)\end{array}\right.$ represent $j$-th particle of the swarm with respect to velocities $v_{j}=\left(\begin{array}{llll}v_{j, 1}, & v_{j, 2}, \ldots \ldots, & v_{j, d}\end{array}\right)$ whose preceding position is characterised as pbest $_{j}=$ $\left(\right.$ pbest $_{j,}, 1$, pbest $_{j,}, \ldots \ldots \ldots . . .$, pbest $\left._{j, d}\right)$. Where, gbest $_{g}$ represents the index of best particle. In this algorithm motion of each particle in the search 
space is achieved by the velocity with reference to its own as well as the best solutions of its preceding groups. Velocity updating is done through three major parts (e.g. momentum, cognitive and social). Performance of this algorithm is determined by the balance between above parts.

\section{PID Controller}

PID controller is a versatile and most commonly used feedback controller in process industries due to its robustness and excellent performance against varied dynamic characteristics. It comprises with three modes of operations (i.e proportional, integral and derivative modes). In its $\mathrm{P}$-mode, the actuating signal for control action and error signals are proportional where it stabilizes the first order unstable process only by reducing rise time, provides suitable action to eliminate oscillation but, it can't eliminate the steady state error. In its I-mode it avoids large disturbances and noises which occurs during the operation and leads the steady state error towards zero but produces very poor transient response. In its Dmode it has all the necessary dynamics with faster reaction towards the change in controller input by which frequency overshoot is reduced resulting an improved transient response and hence the stability. Thus, the PID controller provides better control performance against the variability in dynamic performances. Respective area control errors (ACE) are taken as controllers' input whereas the controller's outputs $\left(\mathrm{u}_{1} \& \mathrm{u}_{2}\right)$ are taken as the control inputs of the power system represented by the following equations.

$$
\begin{aligned}
& e_{1}(t)=A C E_{1}=B_{1} \Delta F_{1}+\Delta P_{T i e} \\
& e_{2}(t)=A C E_{2}=B_{2} \Delta F_{2}-\Delta P_{T i e} \\
& u_{1}=K_{P 1} A E C_{1}+K_{I 1} \int A E C_{1}+K_{D 1} \frac{d A E C_{1}}{d t}
\end{aligned}
$$

$$
u_{2}=K_{P 2} A E C_{2}+K_{21} \int A E C_{2}+K_{D 2} \frac{d A E C_{2}}{d t}
$$

\subsection{Objective function}

In this analysis of the work an Integral of Time multiplied Absolute Error (ITAE) objective function is considered for automatic generation control with respect to the performance index, specifications and constraints of the entire close loop response.

$$
J=I T A E=\int_{0}^{t_{\text {sim }}}\left(\left|\Delta F_{1}\right|+\left|\Delta F_{2}\right|+\left|\Delta P_{T i e}\right|\right) \cdot t \cdot d t
$$

Where, $\Delta F_{1} \& \Delta F_{2}=$ deviations in system frequency, $\Delta P_{\text {Tie }}=$ deviation in tie line power flow $t_{\text {sim }}=$ simulation time.

Sub to

$$
\begin{gathered}
K_{P \min } \leq K_{P} \leq K_{P \max }, \\
K_{I_{\min }} \leq K_{I} \leq K_{I_{\max }}, K_{D_{\min }} \leq K_{D} \leq K_{D_{\max }}
\end{gathered}
$$

The optimum values of the controller parameters are selected between the range of -1.0 to1.0 as per reference to literature [9].

\section{Results Analysis}

\subsection{Implementation of proposed hGSAPSO algorithm}

In this work MATLAB/SIMULINK implemented to develop the system. Then considering PID controllers in each area hGSAPSO program is prepared in m-file. With initial parameters of the controllers and $10 \%$ step load change at area-1 simulation is done for this model in another m-file and the algorithm is applied to the objective. It is found that the performance of GSA depends upon the control parameter $(\alpha)$, initial value of the gravitational constant $\left(G_{0}\right)$, size of the population $(\mathrm{Np})$ and iteration number $(\mathrm{T})$. PSO optimization technique is applied considering cognitive cancelation constant $\left(\mathrm{c}_{1}\right.$ $=2$ ) and social acceleration factors $\left(c_{2}=2\right)$ to characterize the puling action of every particle approaching $P_{\text {best }}$ and $G_{\text {best }}$ points. Global and local explorations can be balanced by selecting a proper value of inertia weight (w) to get improved optima with less number of iterations. However, values must not be low or high by which particles can move towards or away from the target region. From the original developed data, it is observed that the inertia weight (w) decreases from 0.98 to 0.2 linearly during a run. The values of $\mathrm{C}_{1}, \mathrm{C}_{2}$ and $\mathrm{w}$ are selected corresponding to $\alpha=20, G_{0}=100$, $\mathrm{N}_{\mathrm{P}}=20$ and $\mathrm{G}_{\max }=200[16]$. The system configuration of $2.4 \mathrm{GHz}$ and $8 \mathrm{~GB}$ RAM Intel, i-3core CPU, computer, simulation has been done in the MATLAB 7.10.0.499 (R2010a) environment for 50 runs from which 
the best solutions are selected as controller parameters. For the purpose of fine tuning of the best solution of PSO, gravitational search algorithm is employed and final parameters of the controller found from PSO are considered. By considering the two values of GRC taken as in this paper is 0.025 and 0.05 . With 50 independent runs conducted by using hGSAPSO algorithm to obtained the results are given in Table-1along with individual result of GSA algorithm for comparison Performances of hGSA-PSO based PID controller for ITAE objective function in terms of settling time in case of variation of frequencies and tie line power flow in presence of generation constants (GRC $= \pm 0.05$ and \pm 0.025$)$ are compared with GSA, BFOA and GA techniques [15] which are given in Table 2. It is found that, when GRC $= \pm 0.05$ the least value of ITAE objective through hGSA-PSO based PID controller is 0.2819 and the same through GSA, BFOA and GA are 0.3165, 0.4788 and 0.5513 respectively. Similar performances are also found when $\mathrm{GRC}= \pm 0$. 025.This indicates that, the proposed hGSAPSO algorithm achieved better as compared to GSA, GA, BFOA techniques.

Table 1: PID controller parameters with GSA and hGSA-PSO algorithm

\begin{tabular}{lcccc}
\hline \multirow{2}{*}{$\begin{array}{l}\text { Controller } \\
\text { Parameters }\end{array}$} & \multicolumn{2}{c}{ Generation Rate Constant $( \pm$} & \multicolumn{2}{c}{ Generation Rate Constant $( \pm 0.025)$} \\
\cline { 2 - 5 } & GSA & hGSA-PSO & GSA & hGSA-PSO \\
\cline { 2 - 5 } $\begin{array}{l}\text { Proportional Gain } \\
\text { (Ke) }\end{array}$ & 0.3064 & 0.4534 & 0.3216 & 0.2788 \\
Integral Gain $\left(\mathrm{K}_{\mathrm{I}}\right)$ & 0.4982 & 0.6202 & 0.3239 & 0.3806 \\
Derivative Gain $\left(\mathrm{K}_{\mathrm{D}}\right)$ & 0.4139 & 0.4377 & 0.5436 & 0.4520 \\
\hline
\end{tabular}

Table 2: Settling times of frequencies and tie line power variation in presence of GRC

\begin{tabular}{|c|c|c|c|c|c|c|c|c|}
\hline \multirow[t]{3}{*}{$\begin{array}{l}\text { Optimization } \\
\text { Techniques }\end{array}$} & \multicolumn{4}{|c|}{ Generation Rate Constant $( \pm 0.05)$} & \multicolumn{4}{|c|}{$\begin{array}{c}\text { Generation Rate Constant }( \pm \\
0.025)\end{array}$} \\
\hline & \multicolumn{3}{|c|}{ Settling Time in Sec. } & \multirow{2}{*}{$\begin{array}{c}\text { Objective } \\
\text { Function }(J=\text { ITAE })\end{array}$} & \multicolumn{3}{|c|}{ Settling Time in Sec. } & \multirow[b]{2}{*}{ ITAE } \\
\hline & $\Delta \mathrm{F}_{1}$ & $\Delta \mathrm{F}_{2}$ & $\Delta \mathrm{P}_{\text {tie }}$ & & $\Delta \mathrm{F}_{1}$ & $\Delta \mathrm{F}_{2}$ & $\Delta \mathrm{P}_{\text {tie }}$ & \\
\hline hGSA-PSO & 2.7 & 4.6 & 3.8 & 0.2819 & 6.8 & 5.4 & 5.9 & 0.7525 \\
\hline GSA & 3.2 & 5.3 & 4.5 & 0.3165 & 7.1 & 5.8 & 7.4 & 0.8786 \\
\hline BFOA & 4.7 & 6.4 & 5.1 & 0.4788 & 9.0 & 7.9 & 8.3 & 1.5078 \\
\hline GA & 6.9 & 8.0 & 5.7 & 0.5513 & 11.1 & 11.2 & 11.0 & 2.4668 \\
\hline
\end{tabular}


The various cases are considered for studying the dynamic simulation performances in two area power system with variation in step load perturbations (SLP) and generation rate constants are demonstrated as follows.

Case 1: Step load change (with saturation limit \& $G R C= \pm 0.05)$ for area-1
The Figure 2-5 show the system responses performances at $\mathrm{t}=0 \mathrm{~s}$ with $0.1 \mathrm{pu}$ SLP change applied to area-1 from which dynamic simulation of transient performances of hGSA-PSO tuning PID controller is found to better as compared to GA and BFOA optimized with PID controller in term of settling time, overshoot of the transient responses in the system.

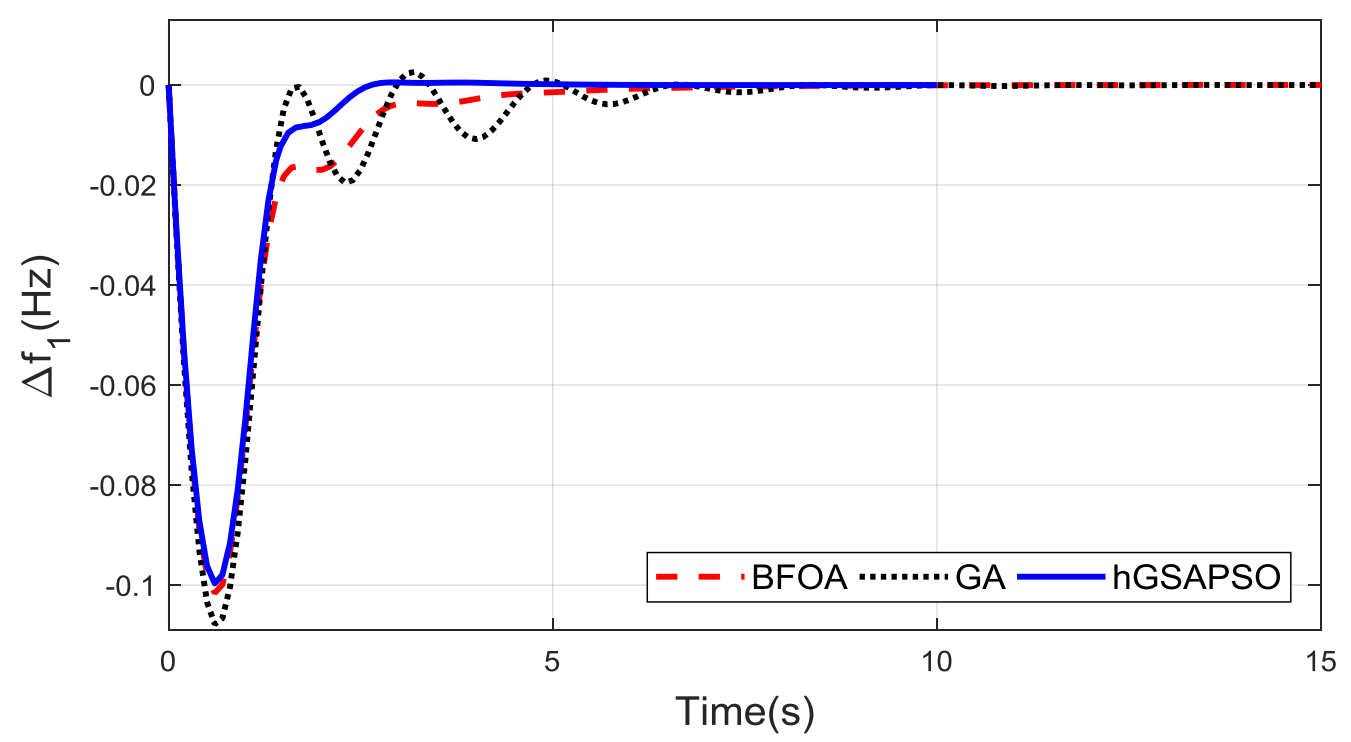

Fig.2. variation of frequency in area-1 under case-1

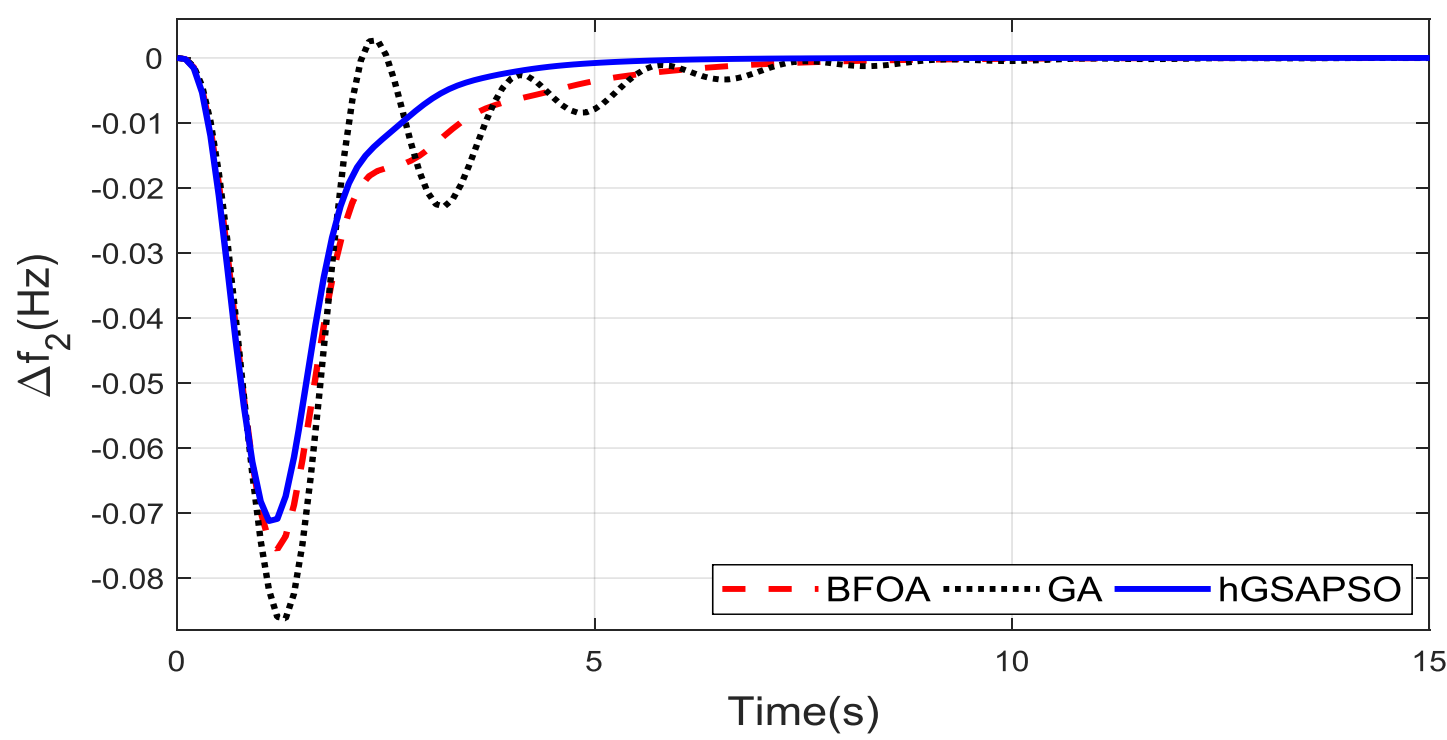

Fig.3. variation of frequency in area-2 under case-1 


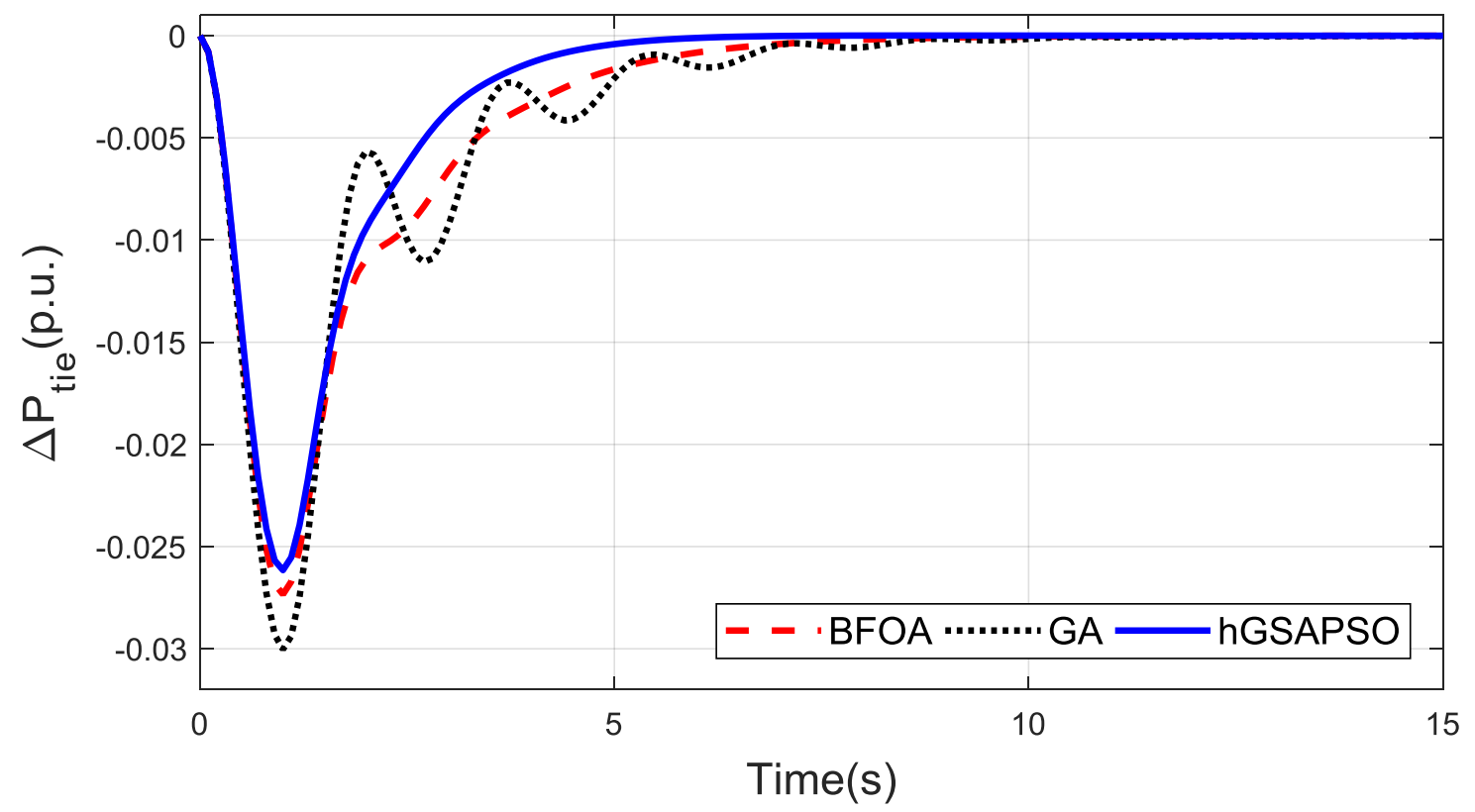

Fig.4. variation of tie line power with case-1

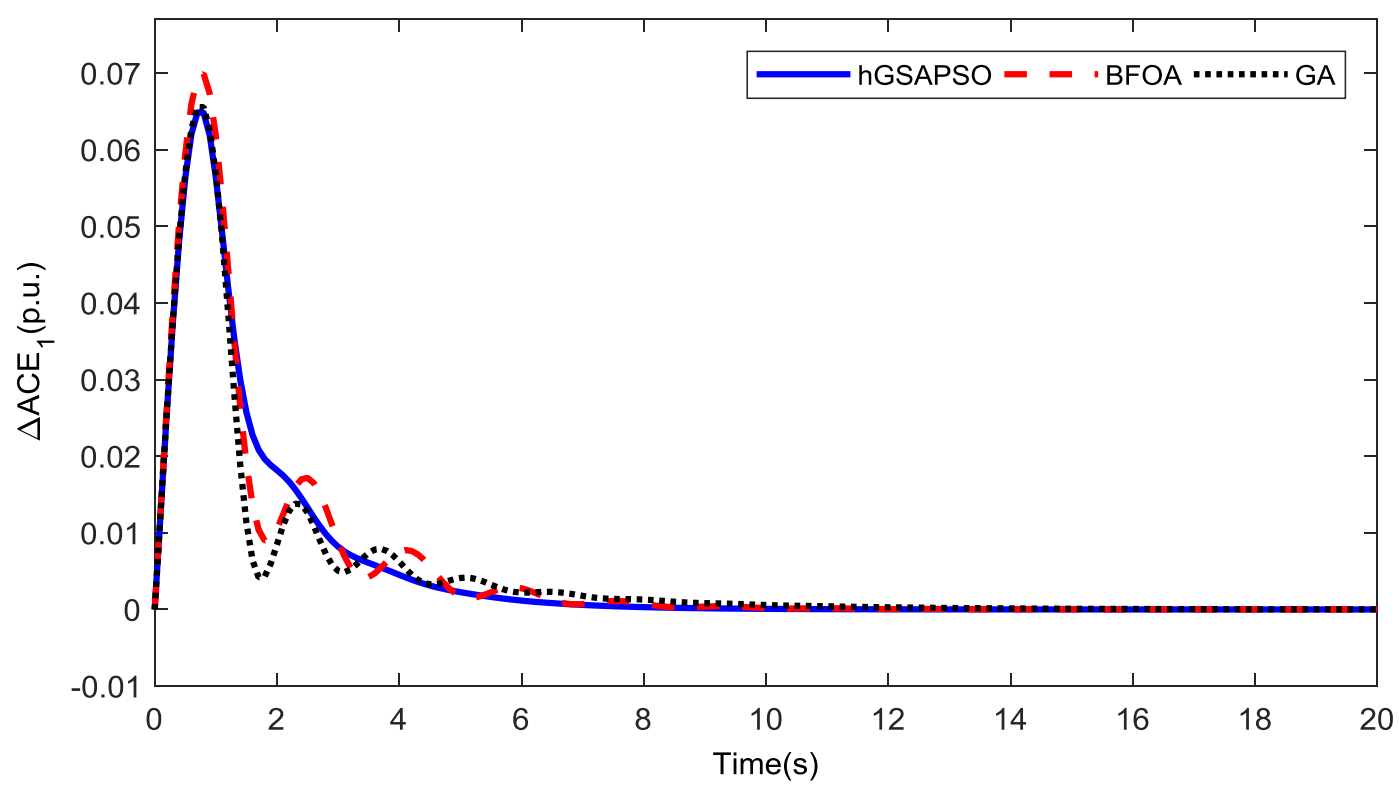

Fig.5.ACE-1 under case-1

Case -2: Step load change $(G R C= \pm 0.05)$ for area-2 
The Figure 6-8 shows, the dynamic performances of the system at $\mathrm{t}=0 \mathrm{~s}$ with $10 \%$ step load change applied in area-2 from which dynamic simulation result of proposed hGSA-
PSO tuning of PID controller is found to superior performance as compared to the same system using optimization algorithm in GA and BFOA with PID tunning control parameters.

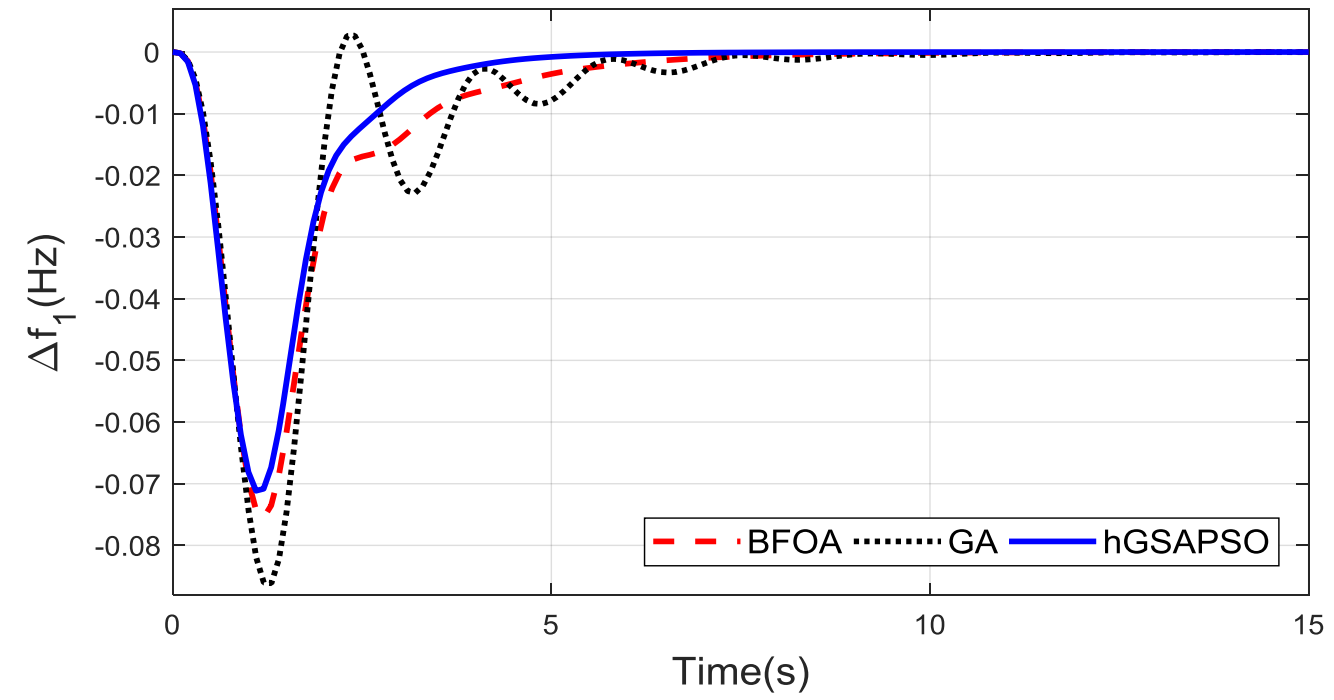

Fig.6 Variation of frequency for area-1 under case-2

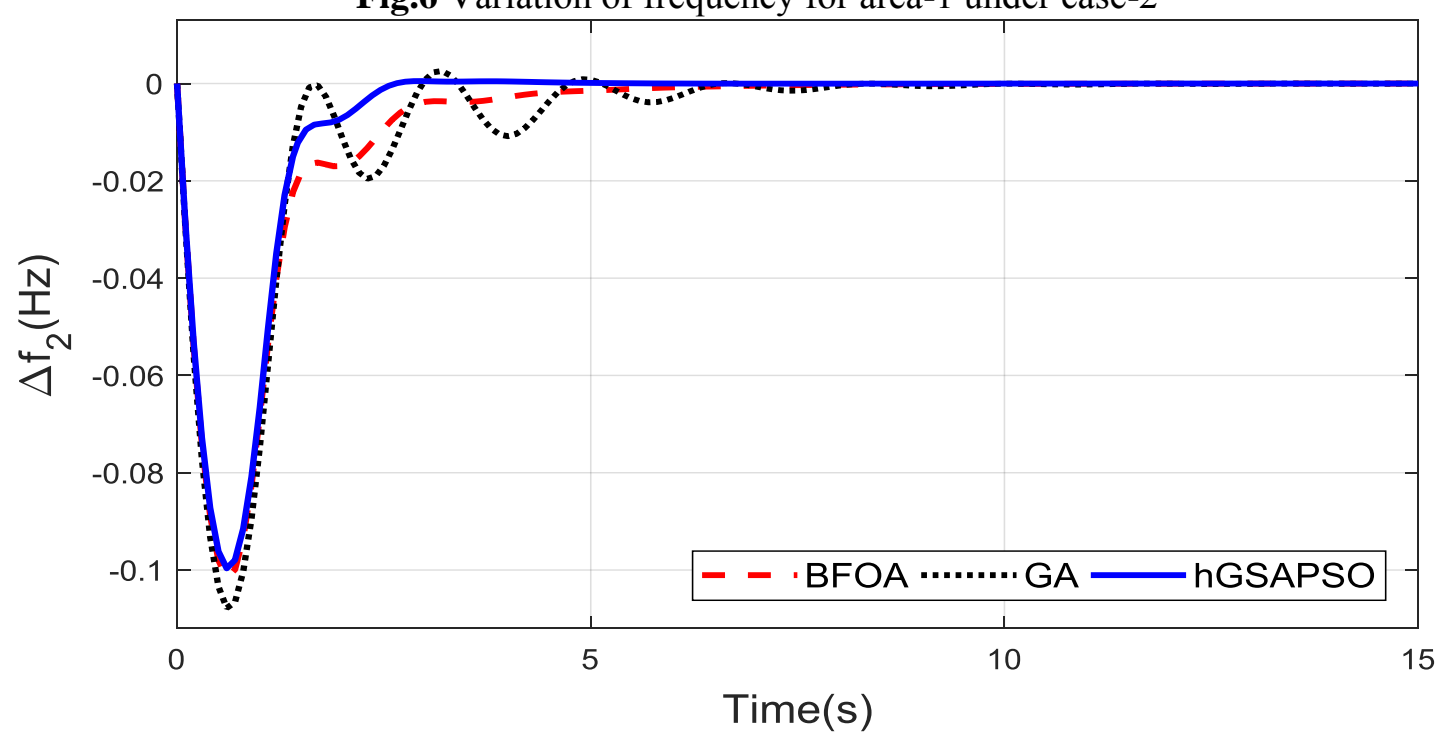

Fig.7. Variation of frequency for area-2 under case-2

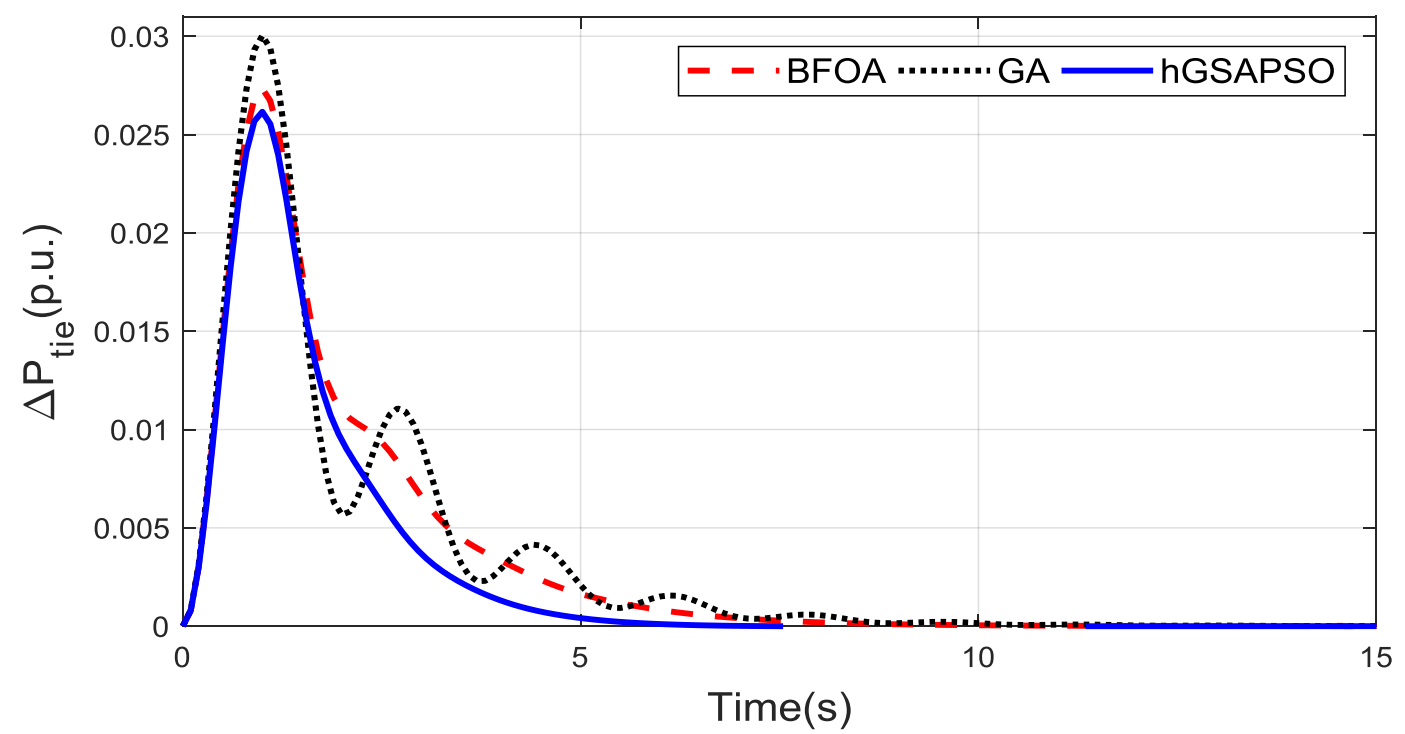

Fig.8. Variation of tie line power with case-2

Case 3: Step load change (with saturation limit \& $G R C= \pm 0.05$ ) for area-1 and Area-2. 
The Figs. 9-10 show the dynamic performances of the system at $\mathrm{t}=0 \mathrm{~s}$ with $10 \%$ step load increase simultaneously in area- 1 and area-2 from which dynamic simulation performance of the anticipated hGSA-PSO optimized PID controller is found to give satisfactory and robust performances as compared with published results of GA and BFOA optimization techniques.

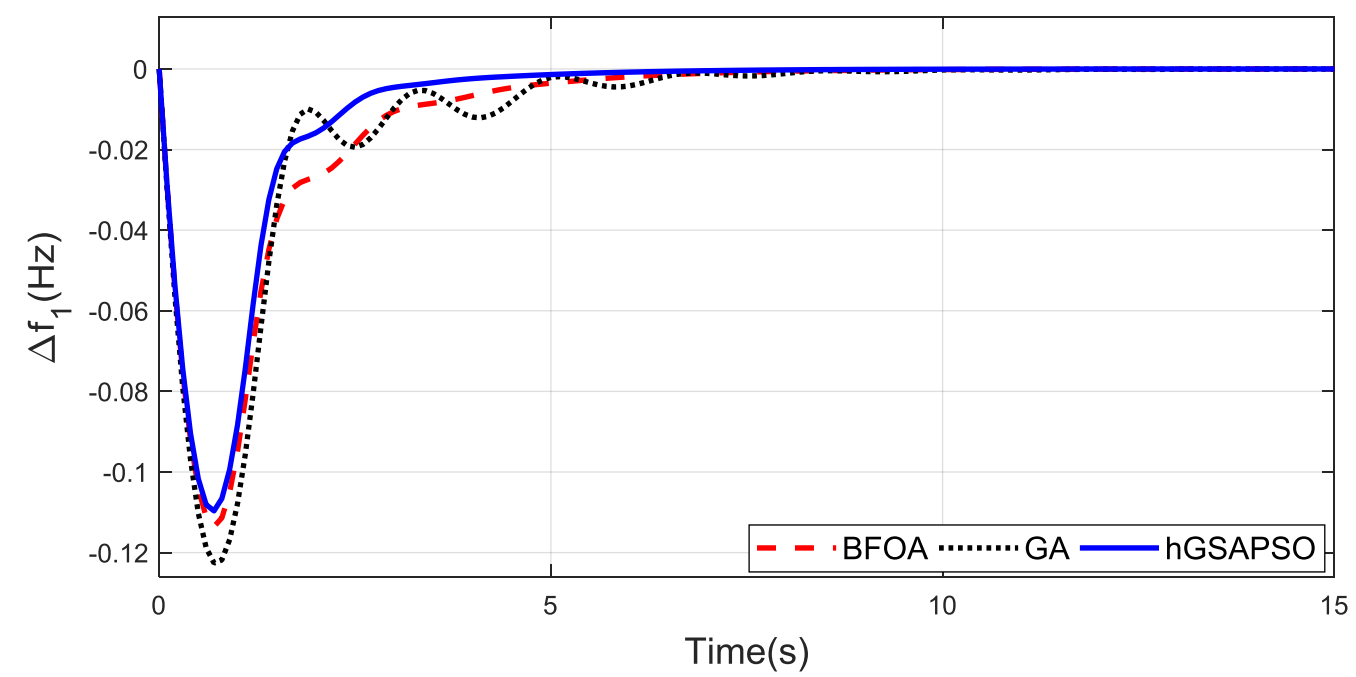

Fig.9 Frequency deviation in area-1 under case-3

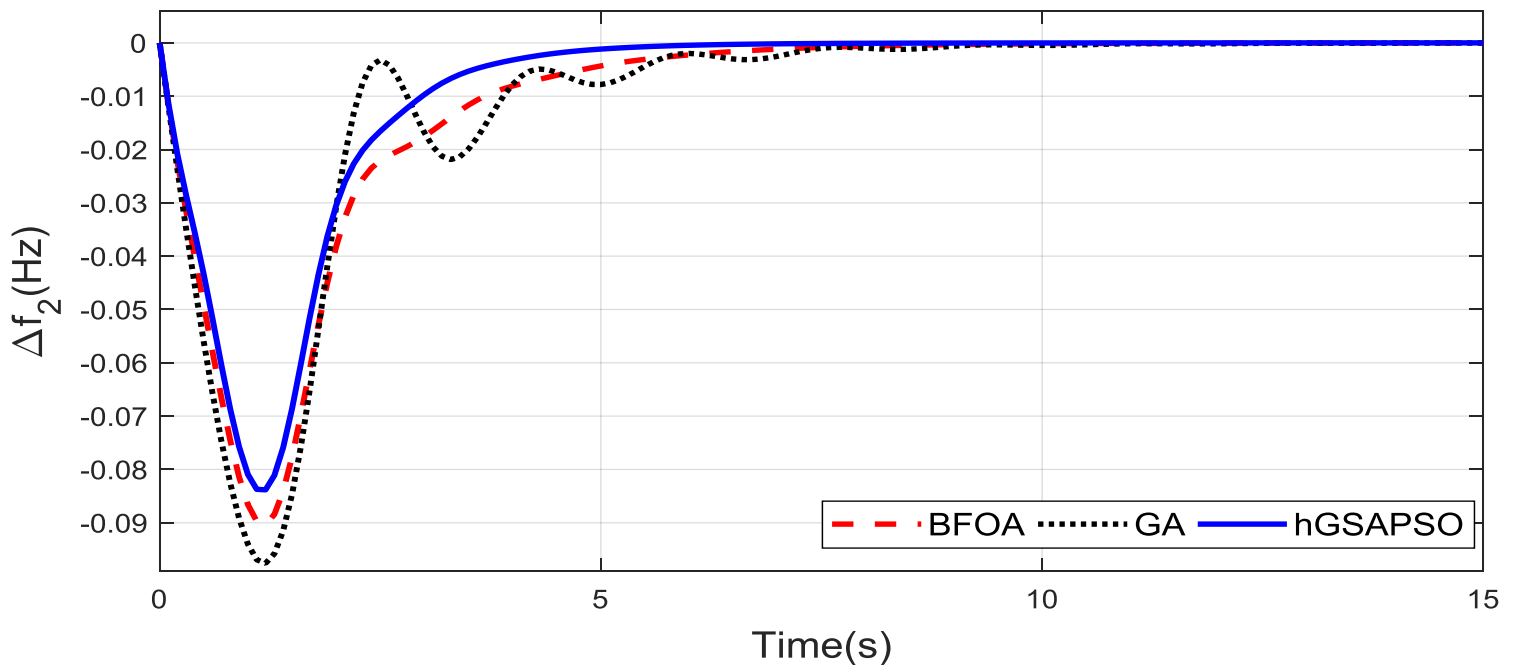

Fig.10 Frequency deviation in area-2 under case-3

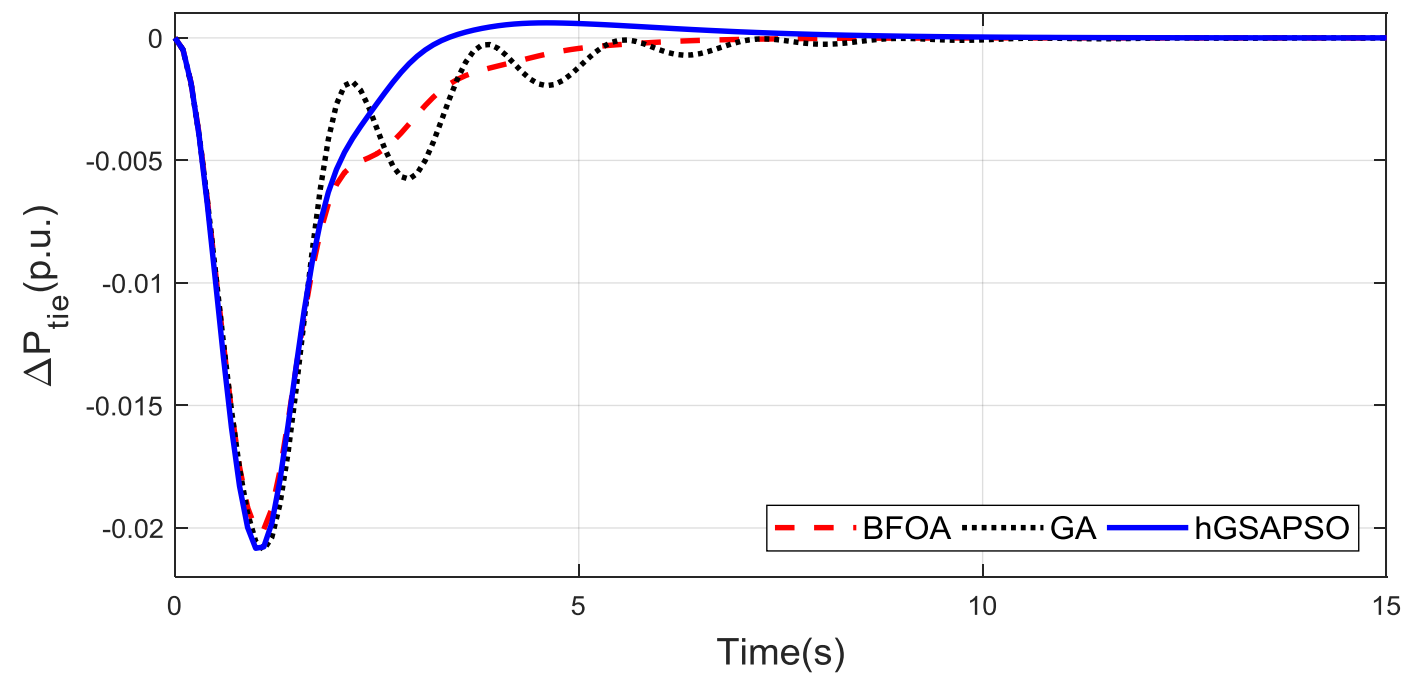

Fig.11 Tie line power deviation under Case-3 
Case 4: Effect of saturation limit (GRC = $\pm 0.025)$

In this condition, the Figure 10-12 shows the dynamic performances at $\mathrm{t}=0 \mathrm{~s}$ with $0.1 \mathrm{SLP}$ change applied in area-1 with results are comparing with GRC as per the case-4 in which dynamic performance of the anticipated hGSA-PSO tuning PID controller observed that it gives the better performance in comparison to GA and BFOA tuning parameters of controllers of the same structure of power system.

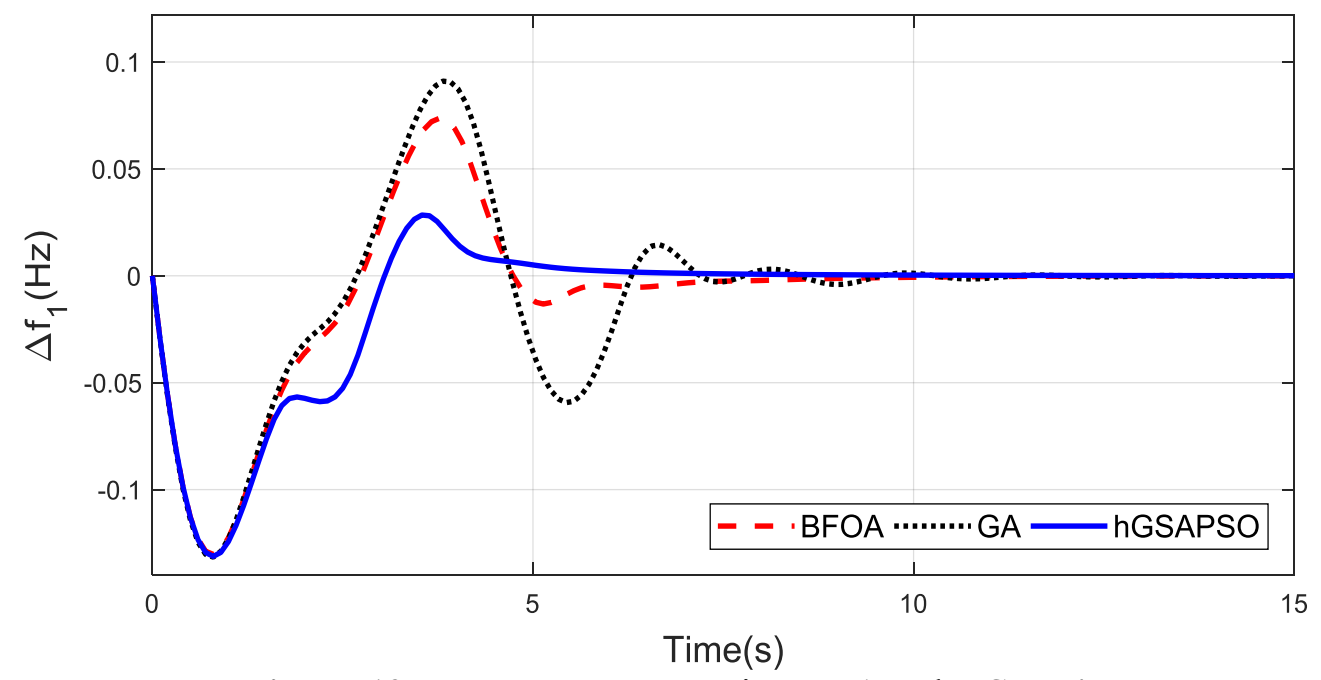

Figure-12: Frequency response in area-1 under Case-4

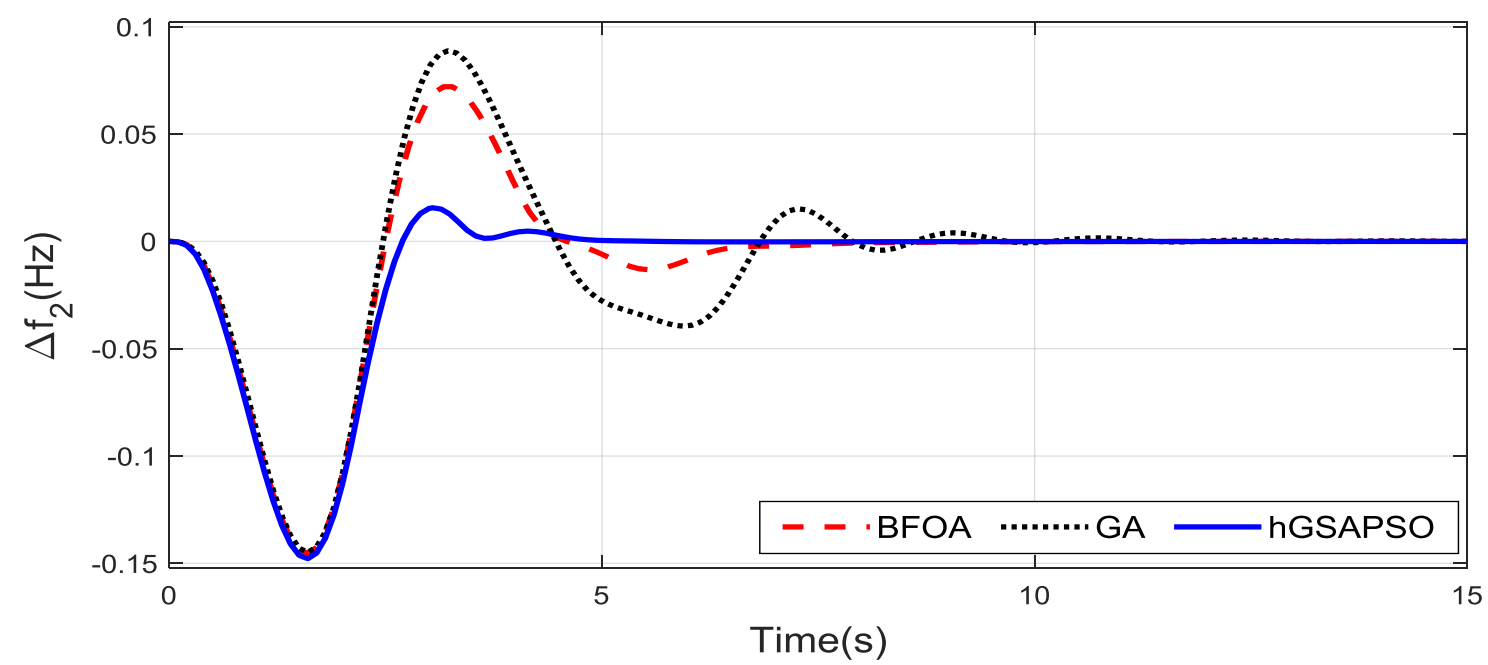

Fig.13 Frequency deviation in area-2 under Case-4

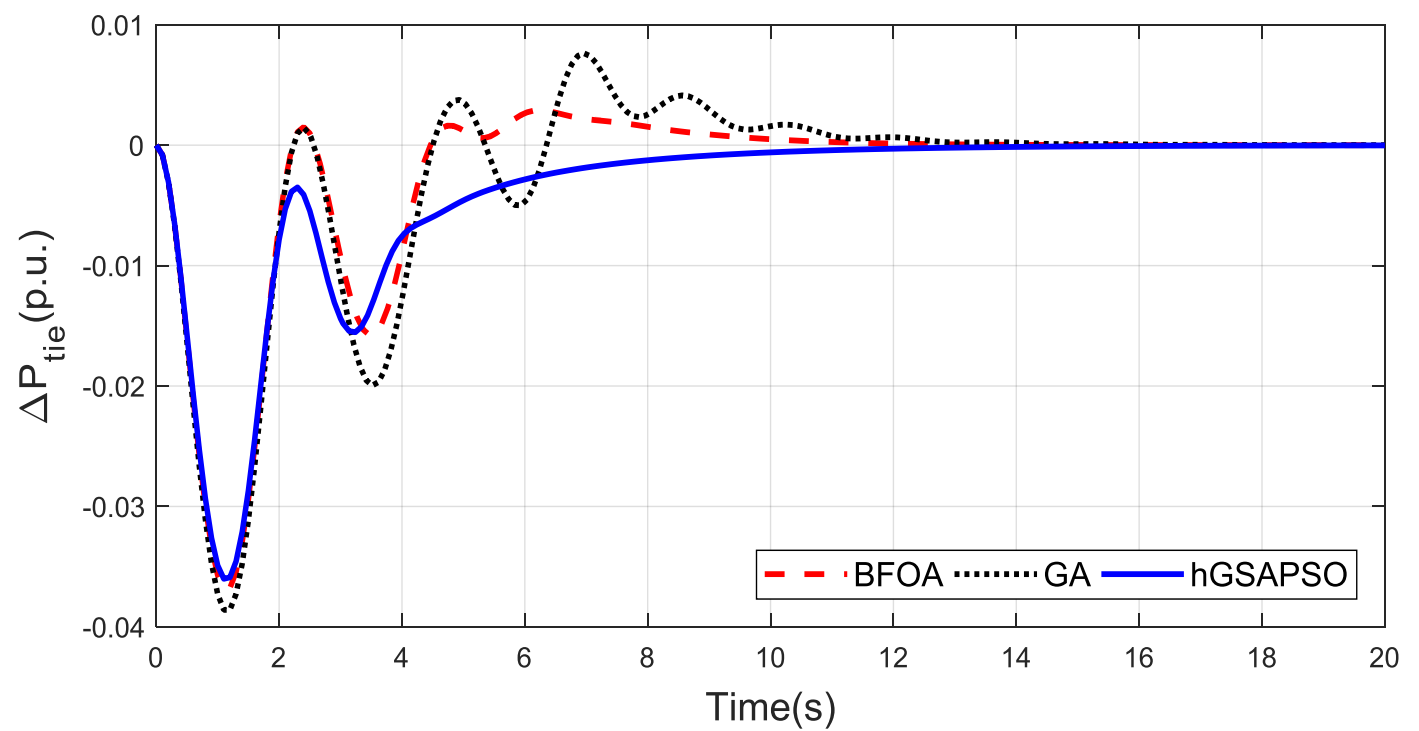

Fig.14 Tie line power deviation under Case-4 


\subsection{Sensitivity analysis}

Robustness of the system with respect to changed values of parameters [18-19] and operating conditions is studied through sensitivity analysis at GRC $= \pm 0.05$ and \pm 0.025 as given in Table- 3 and Table- 4 which provides a better dynamic performance of hGSA-PSO optimized PID controller with a change of 0.1 SLP in area-1 under variable load conditions. The nominal values of load conditions and time constants of governor, turbine and tie-line power (given in the appendix) are changed by steps of $25 \%$ in \pm $50 \%$ range. ITAE objective values in terms of various controller parameters, settling time and tie line power deviations of the present method is comparing with those of BFOA technique used for tuning of PID controller under various loading conditions and time constants. The potentiality and superiority of hGSA-PSO based PID controller is verified in real time environment. It is concluded that, the strategy is relatively robust and effective for providing faster control to the power system.

Table 3: Sensitivity study considering with $\mathrm{GRC}= \pm 0.05$

\begin{tabular}{|c|c|c|c|c|c|c|c|c|c|c|c|c|}
\hline \multirow{3}{*}{ 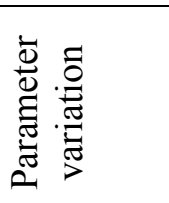 } & \multirow{3}{*}{$\circ \stackrel{\frac{80}{E}}{\frac{D}{U}}$} & \multicolumn{7}{|c|}{ GSAPSO } & \multicolumn{4}{|c|}{ BFOA [15] } \\
\hline & & \multicolumn{3}{|c|}{$\begin{array}{c}\text { Tuned Parameter of the } \\
\text { controller }\end{array}$} & \multicolumn{3}{|c|}{$\begin{array}{l}\text { Settling time } \mathrm{T}_{\mathrm{s}} \\
\text { second }\end{array}$} & \multirow[b]{2}{*}{ ITAE } & \multicolumn{3}{|c|}{$\begin{array}{l}\text { Settling time } \mathrm{T}_{\mathrm{s}} \\
\text { second }\end{array}$} & \multirow[b]{2}{*}{ ITAE } \\
\hline & & $\mathrm{K}_{\mathrm{P}}$ & $\mathrm{K}_{\mathrm{I}}$ & $\mathrm{K}_{\mathrm{D}}$ & $\Delta \mathrm{F}_{1}$ & $\Delta \mathrm{F}_{2}$ & $\Delta \mathrm{P}_{\text {tie }}$ & & $\Delta \mathrm{F}_{1}$ & $\Delta \mathrm{F}_{2}$ & $\Delta \mathrm{P}_{\text {tie }}$ & \\
\hline Nominal & 0 & 0.3722 & 0.5911 & 0.4105 & 2.7 & 4.5 & 4.0 & 0.2766 & 4.7 & 6.4 & 5.1 & 0.4788 \\
\hline \multirow{4}{*}{ 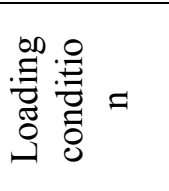 } & +50 & 0.3711 & 0.5221 & 0.4772 & 2.7 & 4.0 & 3.7 & 0.2755 & 5.3 & 7.0 & 5.8 & 0.4842 \\
\hline & +25 & 0.3799 & 0.5912 & 0.3997 & 2.7 & 4.4 & 3.9 & 0.2712 & 4.8 & 6.4 & 5.1 & 0.4806 \\
\hline & -25 & 0.3822 & 0.5987 & 0.3904 & 2.7 & 4.3 & 3.9 & 0.2701 & 4.7 & 6.2 & 5.1 & 0.4735 \\
\hline & -50 & 0.3706 & 0.5921 & 0.4111 & 2.7 & 4.2 & 3.9 & 0.2771 & 4.6 & 6.2 & 5.1 & 0.4699 \\
\hline \multirow{4}{*}{$\mathrm{T}_{\mathrm{G}}$} & +50 & 0.3918 & 0.5901 & 0.4578 & 2.7 & 4.5 & 4.3 & 0.2789 & 4.8 & 6.8 & 5.5 & 0.4760 \\
\hline & +25 & 0.3882 & 0.5883 & 0.4423 & 2.8 & 4.3 & 4.0 & 0.2691 & 4.9 & 6.7 & 5.5 & 0.4751 \\
\hline & -25 & 0.3738 & 0.5999 & 0.3991 & 2.6 & 4.2 & 3.9 & 0.2755 & 5.5 & 6.4 & 5.3 & 0.4807 \\
\hline & -50 & 0.3733 & 0.6067 & 0.4123 & 3.3 & 5.0 & 4.1 & 0.2844 & 5.2 & 6.5 & 5.4 & 0.4843 \\
\hline \multirow{4}{*}{$\mathrm{T}_{\mathrm{T}}$} & +50 & 0.4331 & 0.5922 & 0.4474 & 3.6 & 5.1 & 4.2 & 0.2701 & 5.0 & 7.0 & 5.6 & 0.4634 \\
\hline & +25 & 0.3661 & 0.5905 & 0.4197 & 2.7 & 4.5 & 4.1 & 0.2698 & 4.9 & 6.8 & 5.6 & 0.4709 \\
\hline & -25 & 0.3678 & 0.5957 & 0.4032 & 2.7 & 4.2 & 3.6 & 0.2744 & 5.1 & 6.4 & 5.2 & 0.4841 \\
\hline & -50 & 0.3662 & 0.5921 & 0.4093 & 2.6 & 4.0 & 3.3 & 0.2699 & 5.2 & 6.2 & 5.1 & 0.4911 \\
\hline \multirow{4}{*}{$\mathrm{T}_{12}$} & $\begin{array}{r}+50 \\
\end{array}$ & 0.3771 & 0.5891 & 0.4578 & 3.1 & 3.7 & 3.9 & 0.2700 & 5.4 & 6.3 & 5.4 & 0.4771 \\
\hline & +25 & 0.3801 & 0.6011 & 0.4128 & 2.7 & 4.1 & 3.7 & 0.2711 & 5.5 & 6.6 & 5.3 & 0.4779 \\
\hline & -25 & 0.3779 & 0.5993 & 0.3991 & 3.6 & 4.4 & 4.0 & 0.2767 & 3.7 & 6.5 & 5.2 & 0.4750 \\
\hline & -50 & 0.3655 & 0.5987 & 0.4002 & 5.3 & 5.1 & 4.4 & 0.2789 & 2.2 & 6.9 & 5.6 & 0.5048 \\
\hline
\end{tabular}

Table 4: Sensitivity study considering with GRC $= \pm 0.025$

\begin{tabular}{|c|c|c|c|c|c|c|c|c|c|c|c|c|}
\hline \multirow{3}{*}{ 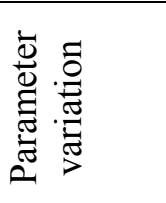 } & \multirow{3}{*}{ م. } & \multicolumn{7}{|c|}{ hGSA-PSO } & \multicolumn{4}{|c|}{ BFOA [15] } \\
\hline & & \multicolumn{3}{|c|}{$\begin{array}{c}\text { Tuned controller } \\
\text { Parameter }\end{array}$} & \multicolumn{3}{|c|}{$\begin{array}{l}\text { Settling time } \\
\mathrm{T}_{\mathrm{s}}(\mathrm{Sec})\end{array}$} & \multirow[t]{2}{*}{ ITAE } & \multicolumn{3}{|c|}{ Settling time $\mathrm{T}_{\mathrm{s}}(\mathrm{Sec})$} & \multirow[t]{2}{*}{ ITAE } \\
\hline & & $\mathrm{K}_{\mathrm{P}}$ & $\mathrm{K}_{\mathrm{I}}$ & $\mathrm{K}_{\mathrm{D}}$ & $\Delta \mathrm{F}_{1}$ & $\Delta \mathrm{F}_{2}$ & $\Delta \mathrm{P}_{\text {tie }}$ & & $\Delta \mathrm{F}_{1}$ & $\Delta \mathrm{F}_{2}$ & $\Delta \mathrm{P}_{\text {tie }}$ & \\
\hline Nominal & 0 & 0.1786 & 0.3164 & 0.4528 & 6.5 & 5.2 & 7.5 & 0.7405 & 9.0 & 7.9 & 8.3 & 1.5078 \\
\hline \multirow{4}{*}{ 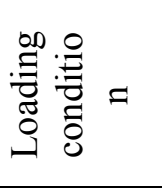 } & +50 & 0.1789 & 0.3117 & 0.4517 & 7.2 & 3.8 & $\%$ & 0.6537 & 9.0 & 7.9 & 8.1 & 1.1254 \\
\hline & +25 & 0.1772 & 0.3142 & 0.4542 & 7.2 & 4.9 & 7.6 & 0.6775 & 8.9 & 7.9 & 8.1 & 1.1910 \\
\hline & -25 & 0.1820 & 0.3155 & 0.4555 & 6.6 & 5.1 & 7.5 & 0.7991 & 8.9 & 7.9 & 8.5 & 1.3502 \\
\hline & -50 & 0.1883 & 0.3200 & 0.4600 & 6.3 & 5.3 & 7.3 & 0.8878 & 9.0 & 7.7 & 8.6 & 1.4288 \\
\hline \multirow{4}{*}{$\mathrm{T}_{\mathrm{G}}$} & +50 & 0.1793 & 0.3273 & 0.4673 & 6.6 & 5.3 & 7.5 & 0.8695 & 7.9 & 7.4 & 9.2 & 1.7988 \\
\hline & +25 & 0.1777 & 0.3272 & 0.4672 & 6.6 & 5.3 & 7.1 & 0.8249 & 8.9 & 7.4 & 8.6 & 1.3425 \\
\hline & -25 & 0.1848 & 0.3100 & 0.4500 & 7.8 & 3.8 & 7.6 & 0.7110 & 9.1 & 8.0 & 8.1 & 1.1997 \\
\hline & -50 & 0.1885 & 0.3100 & 0.4500 & 9.5 & 8.3 & 7.7 & 0.9415 & 9.4 & 8.1 & 8.7 & 1.3011 \\
\hline \multirow[t]{3}{*}{$\mathrm{T}_{\mathrm{T}}$} & +50 & 0.1792 & 0.3104 & 0.4504 & 7.4 & 5.3 & 8.1 & 0.7681 & 9.2 & 8.4 & 7.5 & 1.3957 \\
\hline & +25 & 0.1781 & 0.3157 & 0.4557 & 7.1 & 5.2 & 7.7 & 0.7534 & 9.0 & 7.4 & 7.7 & 1.3071 \\
\hline & -25 & 0.1786 & 0.3103 & 0.4503 & 7.1 & 4.2 & 7.5 & 0.6649 & 9.3 & 8.1 & 8.4 & 1.2088 \\
\hline
\end{tabular}




\begin{tabular}{|c|c|c|c|c|c|c|c|c|c|c|c|c|}
\hline & -50 & 0.1787 & 0.3100 & 0.4500 & 7.3 & 4.3 & 7.2 & 0.6825 & 9.6 & 8.6 & 8.3 & 1.1458 \\
\hline \multirow{4}{*}{$\mathrm{T}_{12}$} & +50 & 0.1883 & 0.3161 & 0.4561 & 7.0 & 6.1 & 9.2 & 0.9098 & 8.0 & 7.6 & 5.6 & 1.2758 \\
\cline { 2 - 13 } & +25 & 0.1791 & 0.3142 & 0.4542 & 6.4 & 5.4 & 8.7 & 0.8370 & 7.6 & 7.1 & 6.2 & 1.0613 \\
\cline { 2 - 13 } & -25 & 0.1812 & 0.3154 & 0.4514 & 7.1 & 4.5 & 6.8 & 0.7369 & 10.4 & 8.5 & 9.6 & 1.4259 \\
\cline { 2 - 13 } & -50 & 0.1889 & 0.3000 & 0.4400 & 10.5 & 7.6 & 7.0 & 1.1940 & 11.1 & 8.2 & 10.2 & 2.1568 \\
\hline
\end{tabular}

\subsection{Extension of the study to Two area with multi sources power system with and without GRC}

In this study of the present work is extended multi source with two area power system is chosen for effectiveness and robustness study for the performance of settling time and ITAE objective function $[18,19-20]$. The multi-source two area power system model is developed as per the given appendix [20]. The anticipated model has analyzed effect of settling time in presence /absence of generation rate constraints (GRC) as GRC which makes the system highly non linear at small disturbance in load. The proposed method is used for optimization of PI/PID controller parameters with/without GRC of multi machine power system and it is repeated 50 times with $10 \%$ step change of load demand in area- 1 at $\mathrm{t}=0 \mathrm{sec}$ whose best optimal results with respect to least objective value are highlighted in table-5. It is also reflected performance indices in terms of settling time of frequency and tie line power flow deviation and errors of ITAE objective are listed in the table-5. From figures 16-18 and table-5 the outperformance of hGSAPSO optimized PID controller in comparison to PI controllers in the same power system is highlighted in absence of without GRC. The Figure 19-21 shows that hGSAPSO optimized PID controller outperforms in terms of frequency overshoot, settling time, deviations in tie line power flow are superior performance as compared with PI controller in presence of GRC of the proposed power

system 


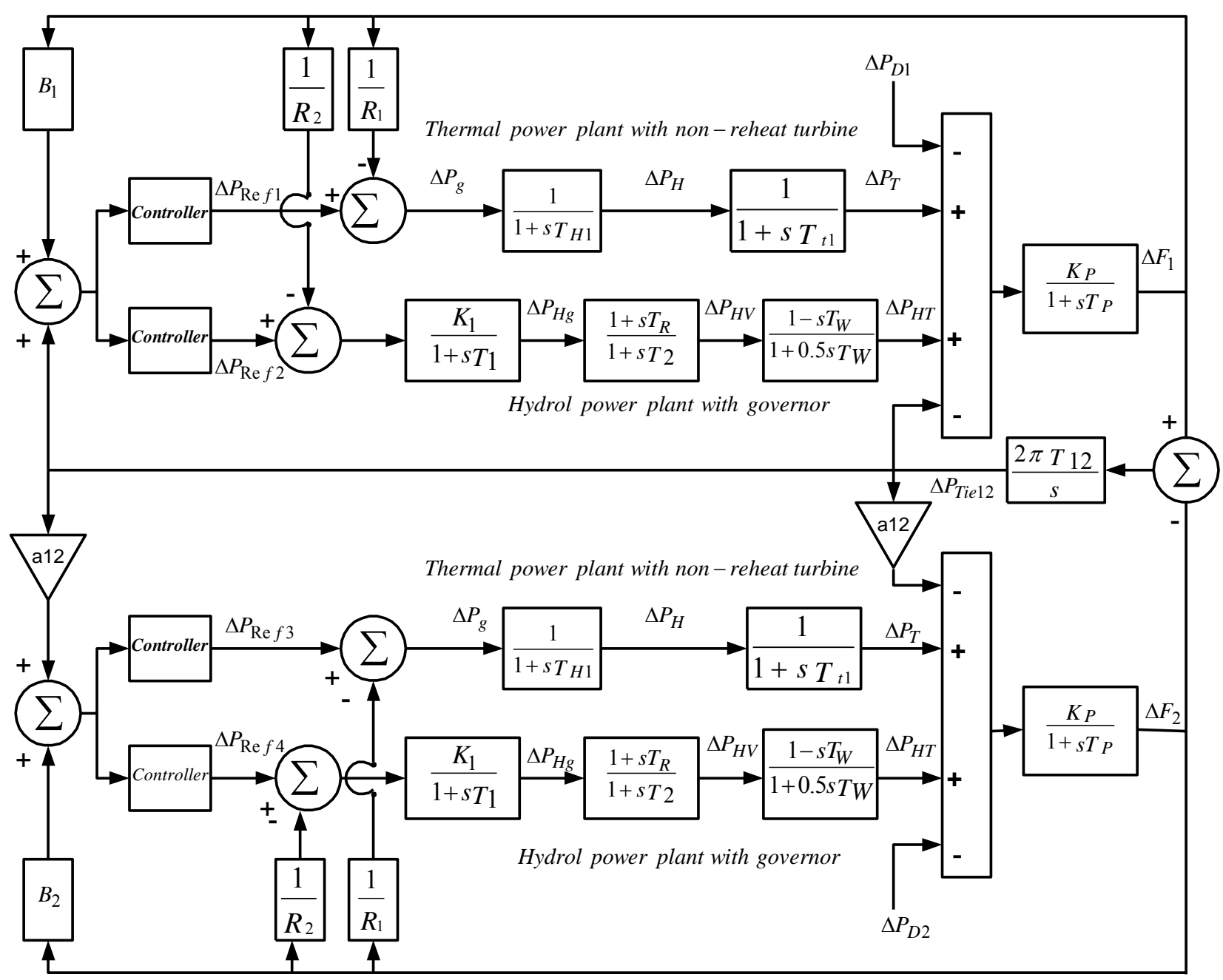

Fig- 15: Transfer function model of the multi-source two area power system

Table 5: Tuned PI and PID controller parameters and performance index of with/without GRC

\begin{tabular}{|c|c|c|c|c|c|c|c|c|}
\hline $\begin{array}{l}\text { Controller } \\
\text { Parameter }\end{array}$ & \multicolumn{3}{|c|}{$\begin{array}{l}\text { PI Controller } \\
\text { Without GRC }\end{array}$} & $\begin{array}{l}\text { Controller } \\
\text { with GRC }\end{array}$ & \multicolumn{3}{|c|}{$\begin{array}{l}\text { PID Controller } \\
\text { without GRC }\end{array}$} & $\begin{array}{c}\text { PID } \\
\text { Controller } \\
\text { with GRC }\end{array}$ \\
\hline KP1 & \multicolumn{3}{|c|}{0.1021} & 0.0522 & \multicolumn{3}{|c|}{1.9911} & 1.7923 \\
\hline $\mathrm{KP}_{2}$ & \multicolumn{3}{|c|}{-0.6914} & -0.3671 & \multicolumn{3}{|c|}{-0.5549} & -0.3428 \\
\hline $\mathrm{KP}_{3}$ & \multicolumn{3}{|c|}{1.4313} & 1.2211 & \multicolumn{3}{|c|}{1.3001} & 1.2734 \\
\hline $\mathrm{KP}_{4}$ & \multicolumn{3}{|c|}{-1.6911} & -1.236 & \multicolumn{3}{|c|}{-1.1110} & -0.7821 \\
\hline $\mathrm{KI}_{1}$ & \multicolumn{3}{|c|}{0.7001} & 0.6401 & \multicolumn{3}{|c|}{1.4671} & 1.551 \\
\hline $\mathrm{KI}_{2}$ & \multicolumn{3}{|c|}{-0.1104} & -0.2987 & \multicolumn{3}{|c|}{-0.1888} & -0.1200 \\
\hline $\mathrm{KI}_{3}$ & \multicolumn{3}{|c|}{0.1282} & 0.1255 & \multicolumn{3}{|c|}{1.8748} & 0.6766 \\
\hline $\mathrm{KI}_{4}$ & \multicolumn{3}{|c|}{-0.0333} & -0.0666 & \multicolumn{3}{|c|}{-1.5544} & -0.5478 \\
\hline $\mathrm{KD}_{1}$ & & & & & \multicolumn{3}{|c|}{0.5978} & 0.5899 \\
\hline $\mathrm{KD}_{2}$ & & & & & \multicolumn{3}{|c|}{0.391} & 0.3344 \\
\hline $\mathrm{KD}_{3}$ & & & & & \multicolumn{3}{|c|}{0.2710} & 0.3421 \\
\hline $\mathrm{KD}_{4}$ & & & & & \multicolumn{3}{|c|}{0.3821} & 0.2211 \\
\hline $\begin{array}{l}\text { Performance } \\
\text { Index }\end{array}$ & $\Delta \mathrm{F}_{1}$ & $\Delta \mathrm{F}_{2}$ & $\Delta \mathrm{P}_{\text {tie }}$ & $\underset{3}{\text { ITAEx } 10^{-}}$ & $\Delta \mathrm{F}_{1}$ & $\Delta \mathrm{F}_{2}$ & $\Delta \mathrm{P}_{\text {tie }}$ & ITAEx $10^{-3}$ \\
\hline $\begin{array}{c}\text { Settling Time } \\
T_{\mathrm{s}} \text { in sec } \\
\text { without GRC }\end{array}$ & 6.39 & 7.88 & 8.12 & 433.0 & 4.21 & 5.33 & 5.98 & 228.5 \\
\hline $\begin{array}{l}\text { Settling Time } \\
\mathrm{T}_{\mathrm{S}} \text { in sec with } \\
\text { GRC }\end{array}$ & 9.93 & 10.34 & 12.95 & 487.4 & 8.31 & 8.41 & 10.22 & 889.0 \\
\hline
\end{tabular}




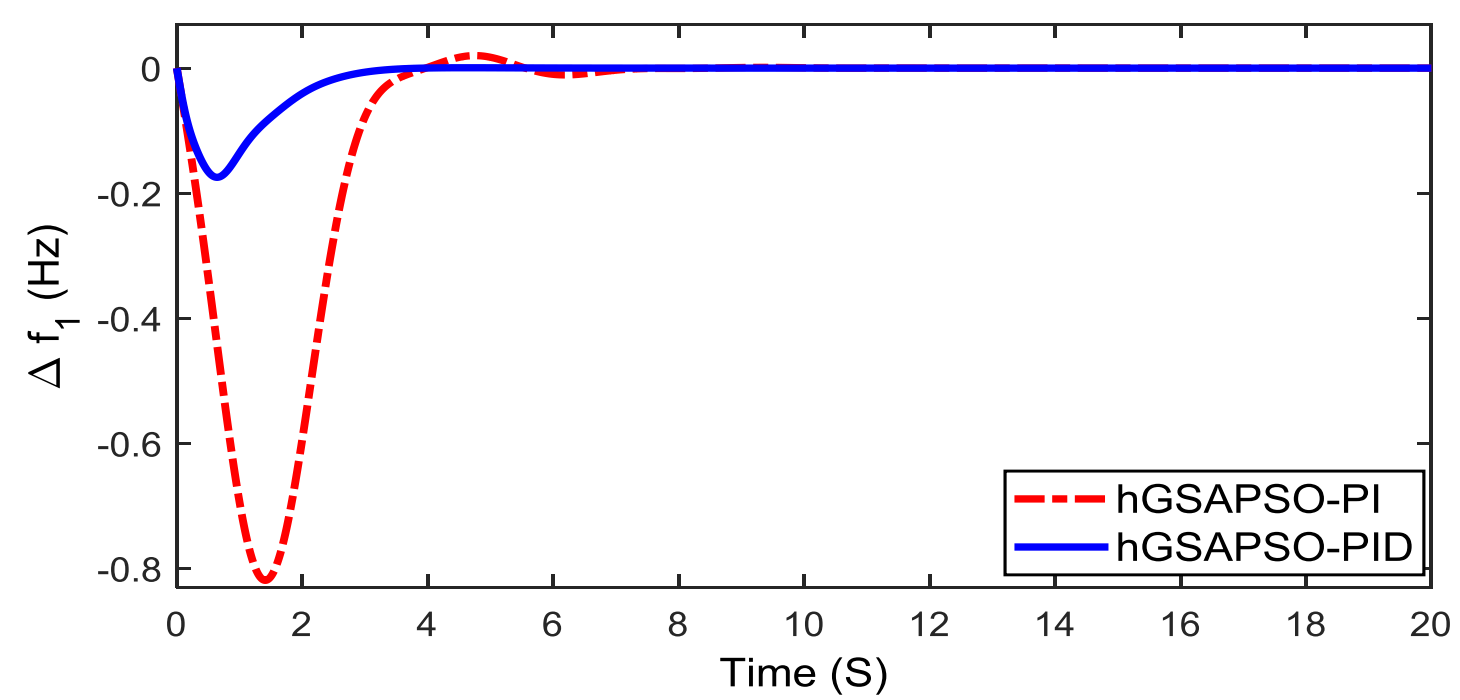

Figure-16: Frequency variation of area-1 without GRC

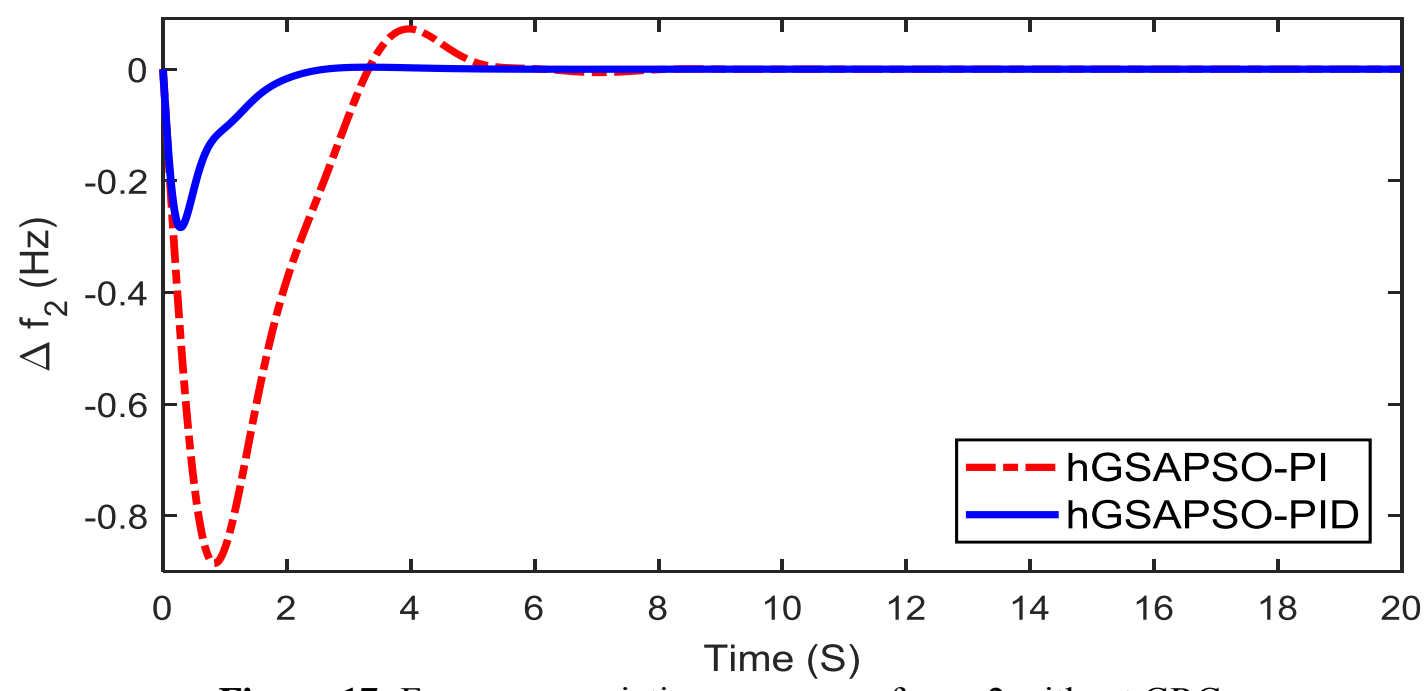

Figure-17: Frequency variation response of area-2 without GRC

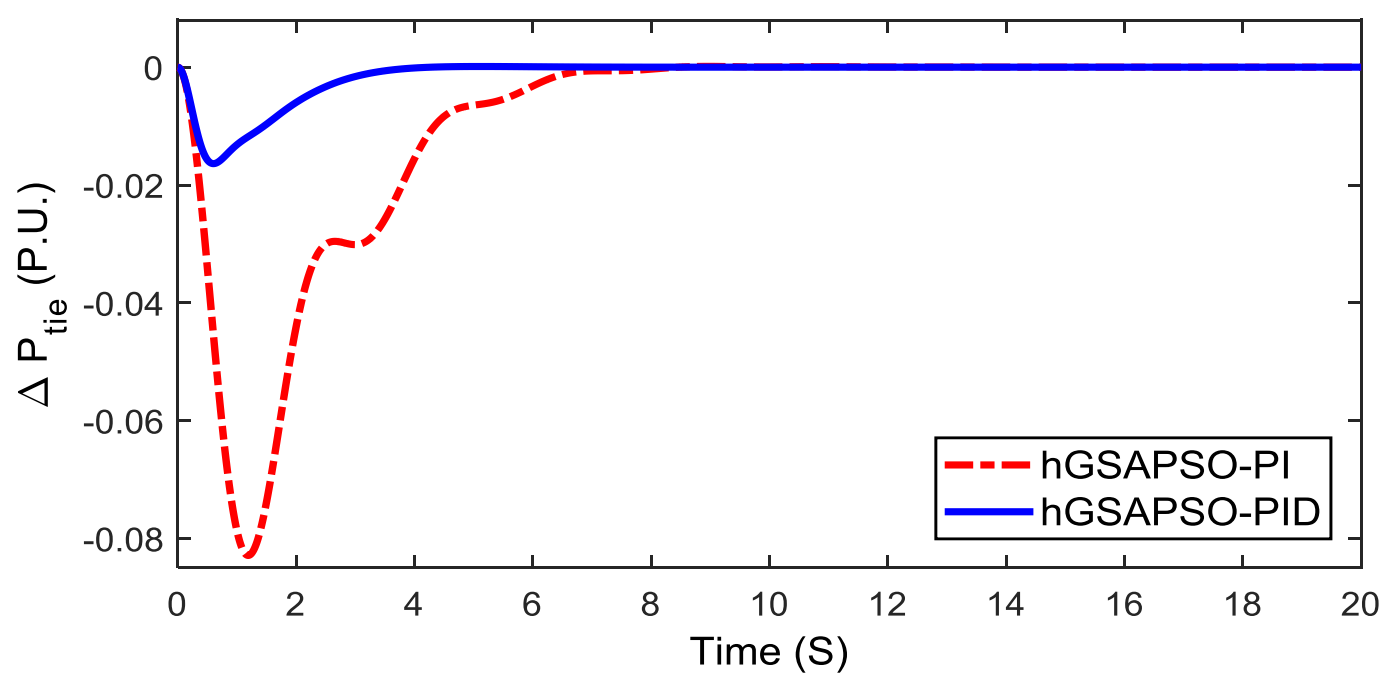

Figure-18: Tie line power deviation without GRC 


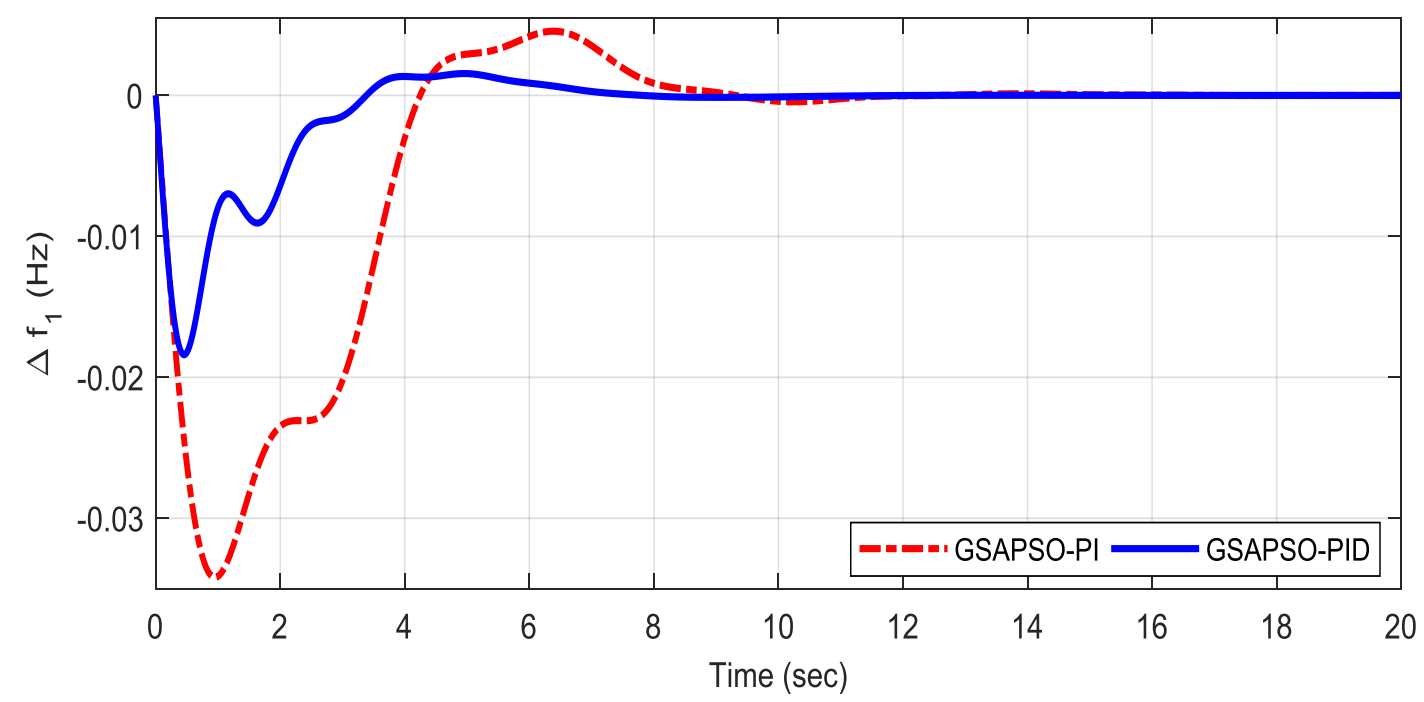

Figure-19: Frequency variation response of area-1 with GRC

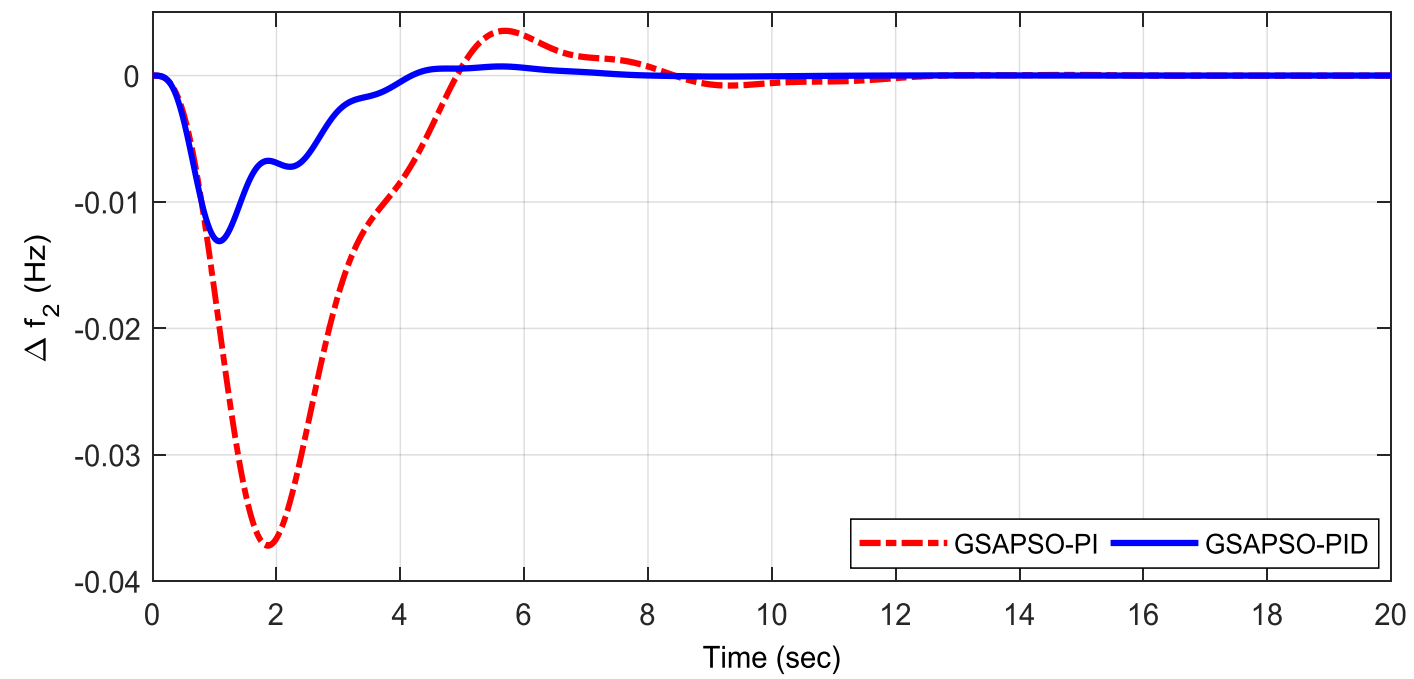

Figure-20: Frequency deviation response of area-2 with GRC

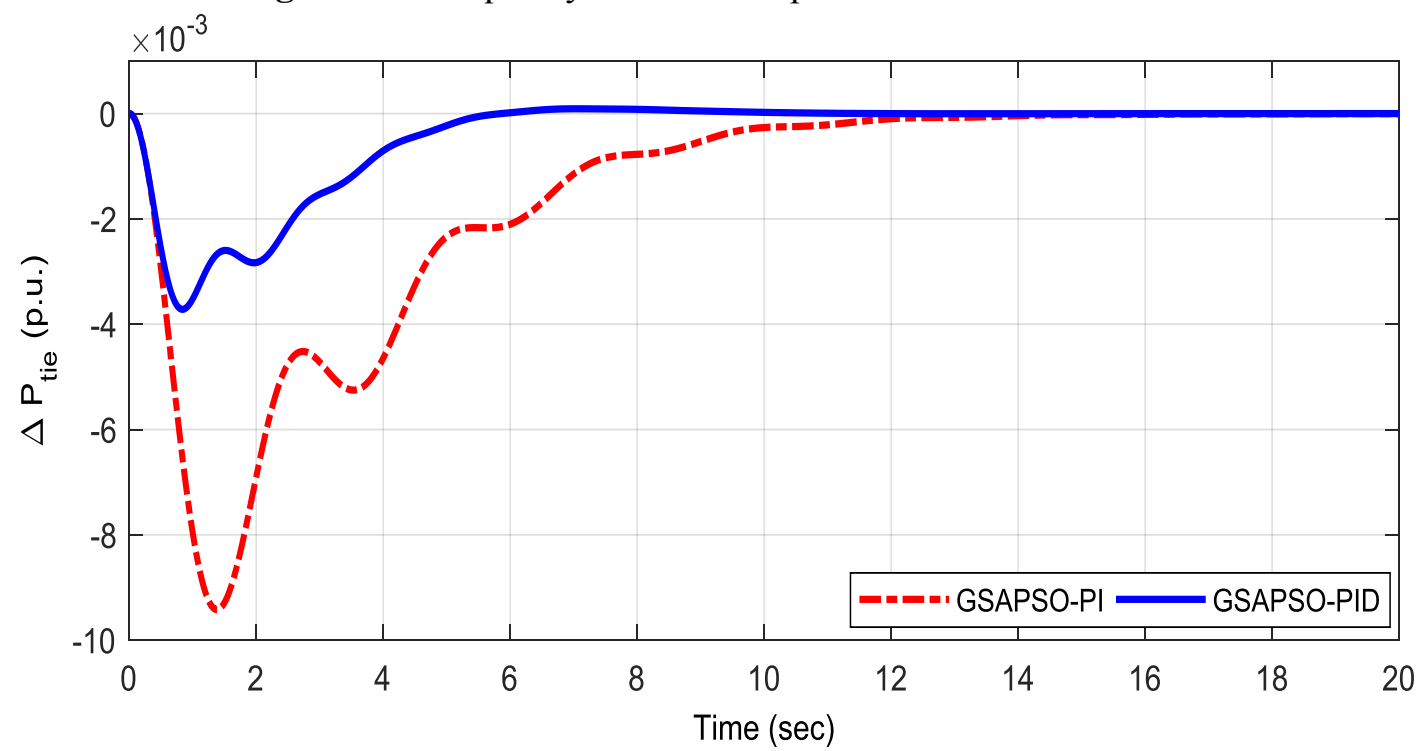

Figure- 21: Tie line power deviation response in area-1 with GRC

\section{Conclusion}

A LFC approach towards application of hGSA-PSO has been adopted in the proposed analysis for tuning controller parameters in automatic generation control of two area interconnected system is considered. A twoarea single sources of power system are considered initially in which PID controller parameters are optimized with ITAE objective 
employing hGSAPSO approach. The performances are compared with BFOA and GA based techniques in the same realistic power system. A sensitivity study is done with variation of system parameters at various operating conditions. The study is extended two-area multi-source system in presence and absence of GRC with the proposed control strategy in order to demonstrate its ability to cope with nonlinear and two area multi-source systems with tunning the PI/PID controller parameters. The dynamic results reveal that the proposed technique with PID controller outperforms as compared with PI controller in both presence and absence of GRC power system in term of settling time of frequency and tie line power deviation.

\section{References}

[1]. Kundur,P, Power System Stability and control, TMH, 8th reprint 2009.

[2]. O.I. Elgerd, Electric energy systems theory. An introduction. New Delhi: Tata McGrawHill; 1983

[3]. S.P. Ghosal, Optimization of PID gains by particle swarm optimization in fuzzy based automatic generation control. Electr Power Syst Res 2004; 72: 203-212

[4]. A.Khodabakhshian , R.Hooshmand. A new PID controller design for automatic generation control of hydro power systems. Int J Electr Power Energy Syst 2010;32(5):375-82.

[5]. Ahamed TPI, Rao PSN, Sastry PS. A reinforcement learning approach to automatic generation control. Electr Power Syst Res 2002; 63: 9-26

[6]. Aravindan P, Sanavullah MY. Fuzzy logic based automatic frequency control of two area power system with GRC. Int J Comput Intell Res 2009;5(1): 37-44.

[7]. E.S. Ali, S.M. Abd-Elazim, Bacteria foraging optimization algorithm-based load frequency controller for interconnected power system, Elect. Power and Energy Syst. 33 (2011) 633638

[8]. Shabani H, Vahidi B, Ebrahimpour M. A robust PID controller based on imperialist competitive algorithm for loadfrequency control of power systems. Article in press in ISA Transactions (2012).

[9]. Rout UK, Sahu RK, Panda S. Design and analysis of differential evolution algorithm based automatic generation control for interconnected power system, Ain Shams Eng J (2012).

[10]. E.S. Ali, S.M. Abd-Elazim, Bacteria foraging optimization algorithm-based load frequency controller for interconnected power system, Elect. Power and Energy Syst. 33 (2011) 633-638

[11]. Yang XS. Firefly algorithms for multimodal optimization, in: Stochastic Algorithms: Foundations and Applications, SAGA 2009, vol. 5792, Lecture Notes in Computer Sciences, 2009, pp. 169-178.
[12]. E. Rashedi, H. Nezamabadi-pour, S. SaryazdiJ, GSA: A Gravitational Search Algorithm, Information Sciences, 179 (2009) 2232-2248

[13]. E. Rashedi, H. Nezamabadi-pour, S. SaryazdiJ, Filter modeling using gravitational search algorithm, Engineering Applications of Artificial Intelligence, 24 (2011) 117-122

[14]. Chaoshun Li, Jianzhong Zhou, Parameters identification of hydraulic turbine governing system using improved gravitational search algorithm, Energy Conversion and Management 52 (2011) 374 381

[15]. Ali ES, Abd-Elazim SM. BFOA based design of PID controller for two area Load Frequency Control with nonlinearities. Int J Electr Power Energy Syst 51 (2013) 224 231.

[16]. Panda S, Yegireddy NK, Mahapatra S, Hybrid BFOA-PSO approach for coordinated design of PSS and SSSC based controller considering time delays. Int J Elect. Power Energy Syst 37 (2012) 58-66.

[17]. Gozde H, Taplamacioglu MC. Automatic generation control application with craziness-based particle swarm optimization in a thermal power system. Int J Elect Power \& Energy Systs 2011; 33: 8-16

[18]. Panda S, Yegireddy NK, Automatic generation control of multi-area power system using multi-objective nondominated sorting genetic algorithm-II, Int $\mathrm{J}$ Electr Power Energy Syst 2013:53:54-63.

[19]. Saikia LC, Nanda J, Mishra S. Performance comparison of several classical controllers in AGC for multi-area interconnected thermal system. Int $\mathrm{J}$ Electr Power Energy Syst 2011; 33:394-401.

[20]. Vijaya Chandrakala KRMV, Balamurugan S, Sankaranarayanan K. Variable structure fuzzy gain schedulingbased load frequency controller for multisource multi area hydro thermal system. Int J Elect Power Energy Syst 53 (2013) 375-381

Contribution of Individual Authors to the Creation of a Scientific Article (Ghostwriting Policy)

The authors equally contributed in the present research, at all stages from the formulation of the problem to the final findings and solution.

\section{Sources of Funding for Research Presented in a Scientific Article or Scientific Article Itself}

No funding was received for conducting this study.

\section{Conflict of Interest}

The authors have no conflicts of interest to declare that are relevant to the content of this article.

Creative Commons Attribution License 4.0 (Attribution 4.0 International, CC BY 4.0)

This article is published under the terms of the Creative Commons Attribution License 4.0

https://creativecommons.org/licenses/by/4.0/deed.en 